NBSIR 79-1723

\title{
Standard Procedure for Use of Thermoluminescence Dosimetry in Radiation-Hardness Testing of Electronic Devices
}

J. C. Humphreys and S. E. Chappell

Center for Radiation Research National Measurement Laboratory National Bureau of Standards

Washington, D.C. 20234

March 1979

Interim Report

\section{Prepared for}

Defense Nuclear Agency

Washington, D.C. 20305

$=Q C$ Sponsored under: Subtask Z990AXTD072, work unit 09 



\section{STANDARD PROCEDURE FOR USE OF THERMOLUMINESCENCE DOSIMETRY IN RADIATION-HARDNESS TESTING OF ELECTRONIC DEVICES}

J. C. Humphreys and S. E. Chappell

Center for Radiation Research National Measurement Laboratory National Bureau of Standards

Washington, D.C. 20234

March 1979

Interim Report

Prepared for

Defense Nuclear Agency

Washington, D.C. 20305

Sponsored under: Subtask Z990AXTD072, work unit 09

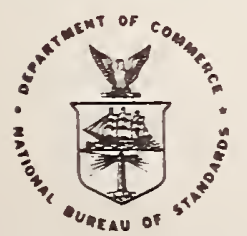

U.S. DEPARTMENT OF COMMERCE, Juanita M. Kreps, Secretary Jordan J. Baruch, Assistant Secretary for Science and Technology NATIONAL BUREAU OF STANDARDS, Ernest Ambler, Director 



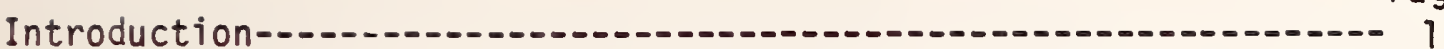

Acknowl edgments -... 2

Standard Recommended Practice for

The Application of Thermoluminescence-Dosimetry

(TLD) Systems for Determining Absorbed Dose in

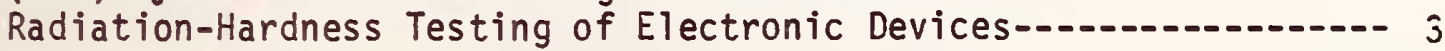

1. Scope-1.- 3

2. Significance--1-1 3

3. Applicable documents--_-1 4

4. Definitions-1-1 5

5. Apparatus--10 7

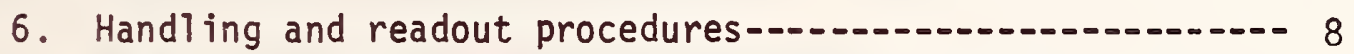

7. Summary of requirements for performance testing of TLD system--.--_- 10

8. Specific performance tests and correction factors-_....-- 12

9. Calibration of the TLD system-_.-.-23

10. Procedures for characterizing and monitoring a test

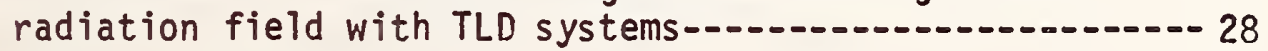

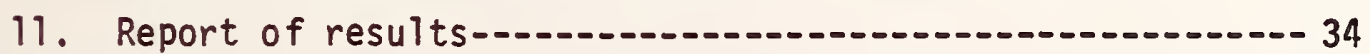

References--_-1 35

Appendixes-1-1.

A1. Recommended Procedures for Application of $\mathrm{CaF}_{2}: \mathrm{Mn}$ Chips-- 38

A2. Energy Absorption Coefficients and Collision Stopping Powers--.- 45

A3. Determination of Electron Equilibrium Thickness-_._-_-_- 49

A4. Determination of Test Sample Size--_-_- 52

Bibl iography-_..- 55 

STANDARD PROCEDURE FOR USE OF THERMOLUMINESCENCE DOSIMETRY

IN RADIATION-HARDNESS TESTING OF ELECTRONIC DEVICES

\author{
J.C. Humphreys and S.E. Chappel1 \\ Radiation Physics Division \\ Center for Radiation Research \\ National Bureau of Standards \\ Washington, D.C. 20234
}

\title{
1. INTRODUCTION
}

Electronic systems of many types are employed in the nation's tactical and strategic weapons systems as well as in deep-space probes. These systems must be able to function reliably in the radiation environments they are expected to encounter in carrying out their missions. There has been a lack of consistency in the experimental results of radiation dosimetry measurements made at the various facilities that are testing the radiation hardness of these electronic systems. It became apparent that there was a need for improvement in the dosimetry procedures employed by the hardnesstesting facilities. Since thermoluminescence dosimetry (TLD) systems are widely used by the hardness-testing facilities, it was clear that a standard TLD procedure would improve the reliability, reproducibility, and uniformity of dosimetry measurements at these facilities. To this end, a standard recommended practice was developed for the use of TLDs in measuring absorbed dose in a medium as a result of photon or electron irradiation. This recommended practice is in the form of an American Society for Testing and Materials (ASTM) standard. The latest draft of this standard is contained in this report. 
It should be noted that this draft standard has not received final approval from ASTM (al though approval is expected within the next few months); therefore, it should not be cited as a reference or published in another form without the expressed approval of the E10 Cormittee Chairman or the Managing Director of ASTM. When the standard has been approved and published by ASTM, it may be obtained from that organization and referenced.

This report includes a selected bibliography of TLD characteristics. This listing is not represented as being comprehensive, but is intended as a guide for those workers getting started in the field of thermoluminescence dosimetry.

The reference citations in the body of the draft standard are for the references listed within that standard (pp. 35 and 36 ) and are not to be confused with the bibliography.

\section{ACKNOWLEDGMENTS}

The authors wish to express their grateful appreciation to Gail de Planque and Margarete Ehrlich for their many helpful suggestions on the contents of the TLD standard and the bibliography. 
E668-78

Standard Recommended Practice for

THE APPLICATION OF THERMOLUMINESCENCE-DOSIMETRY (TLD) SYSTEMS FOR DETERMINING ABSORBED DOSE IN RADIATION-HARDNESS TESTING OF ELECTRONIC DEVICES

\section{Scope}

1.1 This practice covers procedures for the use of thermoluminescence dosimeters (TLDs) to determine the absorbed dose in a material irradiated by ionizing radiation. Although some elements of the procedures have broader application, the specific area of concern is radiation-hardness testing of electronic devices in which the material of interest is usually silicon. This practice is applicable to the measurement of absorbed dose in materials irradiated by gamma rays, $x$ rays, and electrons of energies up to $60 \mathrm{MeV}$. Specific energy limits are covered in appropriate sections describing specific applications of the procedures. The range of absorbed dose covered is approximately from $10^{-2}$ to $10^{4}$ Gy (one to $10^{6} \mathrm{rad}$ ) and the range of absorbed dose rates is approximately from $10^{-2}$ to $10^{10} \mathrm{~Gy} / \mathrm{s}$ (one to $10^{12} \mathrm{rad} / \mathrm{s}$ ). Absorbed dose and absorbed doserate measurements in materials subjected to neutron irradiation are not covered in this standard.

\section{Significance}

2.1 Absorbed dose in a material is an important parameter that can be correlated with radiation effects produced in electronic components and devices that are exposed to ionizing radiation. Reasonable estimates of this parameter can be calculated if knowledge of the source radiation field (i.e., energy spectrum and particle 
fluence) is available. Sufficiently detailed information about the radiation field is generally not available. However, measurements of absorbed dose with passive dosimeters in a radiation test facility can provide information from which the absorbed dose in a material of interest can be inferred. Under certain prescribed conditions, TLDs are quite suitable for performing such measurements.

3. Applicable documents

3.1 ASTM standards

E 170. Definitions of Terms Relating to Dosimetry.

E 380. Metric Practice

E 665. Practice for Determining Absorbed Dose vs. Depth in Materials Exposed to the X-Ray Output of Flash X-Ray Machines.

E 666. Method for the Calculation of Absorbed Dose from Gamma- or X-Radiation.

3.2 International Commission on Radiation Units and Measurements (ICRU) Reports*

ICRU Report 10b. Physical Aspects of Irradiation

ICRU Report 14. Radiation Dosimetry: X Rays and Gamma Rays with Maximum Photon Energies Between 0.6 and $50 \mathrm{MeV}$

ICRU Report 17. Radiation Dosimetry: X Rays Generated at Potentials of 5 to $150 \mathrm{kV}$

ICRU Report 19. Radiation Quantities and Units

ICRU Report 21. Radiation Dosimetry: Electrons with Initial Energies Between 1 and $50 \mathrm{MeV}$

Available from ICRU, 7910 Woodmont Avenue, Washington, D.C. 20014. 
4. Definitions

4.1 absorbed dose - $D$, is the quotient of $d \bar{\varepsilon}$ by $d m$, where $d \bar{\varepsilon}$ is the mean energy imparted by ionizing radiation to the matter in a volume element and $\mathrm{dm}$ is the mass of matter in that volume element.

$$
D=\frac{d \bar{\varepsilon}}{d m}
$$

Previously, the special unit of absorbed dose was the rad, however, the gray (Gy) has been adopted recently as the official SI unit (see ASTM E380).

$$
1 \mathrm{~Gy}=1 \mathrm{~J} \mathrm{~kg}^{-1}=10^{2} \mathrm{rad}
$$

4.2 exposure- $X$, is the quotient of $d Q$ by $d m$ where $d Q$ is the absolute value of the total charge of the ions of one sign produced in air when all the electrons (negatrons and positrons) liberated by photons in a volume element of air having mass dm are completely stopped in air.

$$
X=\frac{d Q}{d m}
$$

The special unit of exposure is the roentgen (R).

$$
1 \mathrm{R}=2.58 \times 10^{-4} \mathrm{C} \cdot \mathrm{kg}^{-1}
$$

4.3 absorbed-dose rate - the absorbed dose per unit time interval.

4.4 equilibrium absorbed dose - the absorbed dose at some incremental volume within the material in which the condition of electron equilibrium (as many electrons of a given energy enter as leave the volume) exists. (See reference 1 and Appendix A3.) 
4.5 thermoluminescence (TL) phosphor - a material which stores, upon irradiation, a fraction of $i$ ts absorbed dose in various excited energy states. When thermally stimulated, the material emits this stored energy in the form of photons in the ultraviolet, visible, and infrared regions.

4.6 thermoluminescence dosimeter (TLD) - a TL phosphor, alone, or incorporated in a material, used for determining absorbed dose in materials. For example, the TL phosphor is sometimes incorporated in a Teflon matrix.

4.7 thermoluminescence dosimeter (TLD) reader - an instrument used to measure the light emitted from a TLD consisting essentially of a heating element, a light measuring device, and appropriate electronics.

\section{8 thermoluminescence dosimeter (TLD) response - the measured} light emitted by the TLD and read out during its heating cycle consisting of one of the following: (a) the total light output over the entire heating cycle, (b) a part of that total light output, or (c) the peak amplitude of the light output.

4.9 thermoluminescence dosimeter (TLD) batch - a group of TLDs, generally originating from a single mix or lot of TL phosphor, having similar TL responses and similar thermal and irradiation histories.

4.10 TLD preparation - the procedure of cleaning, annealing, and encapsulating the TL phosphor prior to irradiation.

4.11 annealing - thermal treatment of a TLD prior to irradiation or prior to readout.

NOTE 1 - Pre-irradiation annealing of TLDs is usually done to erase the effects of previous irradiation and to readjust the sensitivity of the phosphor; pre-readout annealing usually is done to reduce low-temperature TLD response. 
4.12 calibration conditions - the normal environmental conditions prevailing during routine calibration irradiations such as the ambient temperature, humidity, and lighting.

4.13 test conditions - the normal environmental conditions prevailing during routine hardness-test irradiations such as the ambient temperature, humidity, and lighting.

\section{Apparatus}

5.1 A ILD system consists of the TLDs, the equipment used for preparation of the TLDS, and the TLD reader.

5.2 A calibration facility delivers a known quantity of radiation to materials under certain prescribed environmental and geometrical conditions. Its radiation source is usually a radioactive isotope, commonly either ${ }^{60} C_{0}$ or ${ }^{137} \mathrm{Cs}$, whose radiation output has been calibrated by specific techniques to some specified uncertainty (usually to within $\pm 5 \%$ ).

5.3 A storage facility provides an environment for the TLDs before and after irradiation, that is light tight and that has a negligible background absorbed-dose rate. A TLD stored in the facility for the longest expected storage period should absorb no more than $1 \%$ of the lowest absorbed dose expected to be measured in hardness-testing applications.

5.4 An environmental chamber is used in testing the effects of temperature and humidity on TLD response. The chamber should be capable of controlling the temperature and humidity within $\pm 5 \%$ over the range expected under both calibration and test conditions. 


\section{Handling and readout procedures}

6.1 Bare TLDs, such as those not sealed in glass, should not be handled with the bare fingers; dirt or grease on their surfaces can affect their response. It is recommended that tweezers or vacuum pick-up tools be used in handling. If required, the TLDs can be cleaned by using the procedures given in Appendix Al.

6.2 TLDs should be protected as much as possible from light having an appreciable ultraviolet component such as sunlight or fluorescent lighting. Prolonged exposure to uv light, either before or after irradiation, can cause spurious TLD response and enhanced post-irradiation fading. Incandescent lighting is recommended for the TLD preparation and readout areas. However, brief exposures of a few minutes under normal room fluorescent lights should not significantly affect TLD response except for low absorbed-dose measurements $(<1$ Gy or $<100 \mathrm{rad}$ ).

6.3 Preparation of the TLDs for irradiation consists of cleaning the TL phosphor (if required), annealing (if reusable TLDs are employed), and encapsulating the TL phosphor. Reusable TLDs require careful treatment during annealing in order to obtain the best results in dose measurements. The annealing procedure should include a reproducible temperature cycle of the annealing oven, accurate timing of the annealing period, and a reproducible cooling rate.

6.4 for low absorbed-dose measurements ( $<1$ Gy or $<100$ rad), dry nitrogen should be flowed through the heating pan area of the TLD reader during readout. This technique suppresses the spurious TL response that occurs in most forms of TLDs as a result of adsorbed oxygen on the phosphor surface. 
6.5 Calibration-irradiated TLDs and all subsequent test-irradiated TLDs from the same batch should be read out with the same reader using the same readout techniques and reader parameters. The calibration is valid only for that batch used in that particular reader. Readers that are different from the one used for calibration, including those of the same make and model, do not necessarily indicate the same TLD response for TLDs irradiated to the same absorbed dose.

6.6 TLDs are utilized in two basic ways: as reusable or as singleuse "throw-awway" dosimeters. Dosimeters employed in a reusable mode are cycled repeatedly through an anneal-irradiation-readout procedure. The single-use dosimeters are irradiated once, read out, and then discarded; they are generally used as received from the manufacturer. 
7. Summary of requirements for performance testing of a TLD system

7.1 The performance of a specific TLD system should be evaluated to determine its suitability for use in a specific radiation-hardness test. Acceptable performance of the TLD system should be ascertained before applying the system in a particular radiation-hardness-testing facility. Specific performance criteria will be discussed in section 8 .

7.2 Performance tests should be repeated whenever a significant change is made in the TLD system or in the specific application. Examples of such changes are: a change in the physical form or type of phosphor in the TLD, a change in any critical component or in any adjustable readout factor of the TLD reader, or a change in the irradiation source characteristics.

7.3 A particular performance test may be omitted if widely accepted documentation exists in the scientific and technical literature to show that the performance of the TLD system is satisfactory for that specific requirement. For example, if previously accepted studies document that a particular TLD has no absorbed-dose-rate dependence for the expected conditions of irradiation, then performance testing for absorbed-dose-rate dependence of that TLD system is unnecessary. A11 reports of test results should include appropriate references that substantiate the performance of the system and thereby justify the omission of such performance tests.

7.4 If a particular TLD system fails to meet the performance specification of any performance test, then use of that TLD system is not recommended. Howeyer, such a system may be employed, if necessary, but onty if appropriate corrections to the TLD response can be determined sufficiently well in order that the results of the specific radiationhardness test can be determined within the required uncertainty. 
7.5 The number of TLDs, or the number of replicates of measurements with a single TLD, used for each test should be sufficient to assure that the test results are significant at the $95 \%$ confidence leve1. The number of measurements required is specified in each test procedure and is based on the assumption of random samples drawn from a TLD batch whose responses have a normal population distribution. See reference 2 for details of the procedures used to select random samples and to determine the sample size required.

NOTE 2 - If a sample of $n$ measurements $Y_{1}, Y_{2}, \ldots, Y_{n}$ is taken, the best estimate of the population mean, $m$, of a normal distribution is given by the mean value, $\bar{Y}$, of the sample:

$$
Y=\frac{1}{n} \sum_{i=1}^{n} Y_{i} \text {. }
$$

The best estimate of the variance, $\sigma^{2}$, of the distribution is given by the variance, $s^{2}$, of the sampie:

$$
s^{2}=\frac{1}{n-1} \sum_{i=1}^{n}\left(Y_{i}-\bar{Y}\right)^{2}
$$

The quantity $\sigma\left(k \sqrt{s^{2}}\right)$ is called the standard deviation of the distribution. It should be noted that the degree to which $s$ is a best estimate of $\sigma$ depends on the sample size and, as might be expected, $s$ becomes a better estimate of $\sigma$ as the sample size increases. 


\section{Specific performance tests and correction factors}

8.1 Uniformity of TLD response within a batch.

8.1.1 Select a random sample of 30 TLDs from a batch. Treat all of the sample TLDs in an identical manner, prepare them, irradiate them in the calibration facility to the same absorbed-dose level, and read them out. Determine the variance, $\mathrm{s}^{2}$, of the sample and estimate the standard deviation of the TLD response distribution $\left(\sigma=\sqrt{\mathrm{s}^{2}}\right)$. The standard deviation $\sigma$ should not exceed $8 \%$ of the sample mean value, $\bar{Y}_{0}$; i.e., $\sigma \leq(0.08) \bar{Y}_{0}$. The sample size specified (30) is the number of measurements required to estimate the standard deviation, $\sigma$, of the TLD response distribution within $25 \%$ of its true value at a $95 \%$ confidence level (see section 2.4 of reference 2).

8.1.2 For reusable TLDs that have been subjected to a number of anneal-irradiation cycles, the uniformity of the batch response should be verified periodically by repeating the test of 8.1.1. The frequency required for the test depends on the type of TLD and on its previous anneal-irradiation history. Retesting of the batch uniformity becomes particularly important for TLDs irradiated to high dose levels $\left(>10^{2}\right.$ Gy $\left.\left(10^{4} \mathrm{rad}\right)\right)$.

\subsection{Reproducibility of TLD response of individual reusable dosimeters}

Certain types of TLDs may be utilized as individual reusable dosimeters. In this case, the identity of each individual dosimeter is maintained during repeated measurement cycles throughout its useful life. This is in contrast to utilization in the batch mode where individual dosimeters within the batch are not identified. To test the reproducibility of the response of an individual reusable dosimeter, the following procedures should be followed. 
8.2.1 Select the individual TLD to be tested, prepare it, irradiate it in the calibration facility to a specific absorbed-dose level (e.g., at the midpoint of the absorbed-dose range of interest), and read it out. In an identical manner, repeat this procedure thirty times. Determine the variance, $s^{2}$, of the responses and estimate the standard deviation of the TLD response distribution $\left(\sigma=\sqrt{\mathrm{s}^{2}}\right)$. The standard deviation, $\sigma$, should not exceed $5 \%$ of the mean response value, $\bar{Y}_{0}$; i.e., $\sigma \leq(0.05) \bar{Y}_{0}$.

8.2.2 Some types of TLDs may exhibit a change in sensitivity (i.e., response per unit absorbed dose) with repeated anneal-irradiationreadout cycling. This effect is most pronounced if the TLD is not annealed thoroughly. The test results of 8.2.1 may not show such a change in response sensitivity. However, if such a change is shown in that test or if it appears after a larger number of cycles than specified in that test, then a different analysis of the data is required. In this case, a curve should be fitted to the data of response vs. number of cycles by a leastsquares method. A measure of reproducibility would then be given by the average standard deviation of the data points from the least-squares curve. The performance criterion is the same as in 8.2.1.

8.2.3 Since the identity of each TLD is maintained when it is utilized as an individual dosimeter, it is not necessary that groups of such individual TLDs meet the batch requirements of 8.1 . However, for the other performance tests and correction factors discussed in Section 8, it is assumed that such tests and factors are evaluated by utilizing TLDs in a batch mode. 


\subsection{Dependence of TLD response on absorbed-dose rate}

8.3.1. From a TLD batch meeting the requirements of 8.1.1, select a number of TLDs. Divide the TLDs into a number of groups, $x$, each group containing $n$ samples. Determine the absorbed-dose-rate range of interest for the intended application and divide this range into $\mathrm{x}$ intervals (for example, one interval per decade). Prepare all the TLDs in an identical manner, and irradiate each group to the same dose level, but at a different absorbed-dose rate for each $x$ group, covering the absorbed-dose-rate range of interest. Read out the TLDs. Determine the mean response, $\bar{Y}_{i}$, for each $x$ group of $n$ samples. Determine an overall mean value, $\bar{Y}_{0}$, for all $\times$ group means. Then the absolute difference between any group mean and the overall mean should not exceed $20 \%$ of the overall mean. That is,

$$
\left|\bar{Y}_{i}-\bar{Y}_{0}\right| \leq(0.2) \bar{Y}_{0}
$$

8.3.2 If $\left|\bar{Y}_{i}-\bar{Y}_{0}\right|>(0.05) \bar{Y}_{0}$, then appropriate correction factors to the TLD response as a function of absorbed-dose rate should be determined by the procedures that follow.

8.3.3 Determine the number of samples $n$ required in each $x$ group in order to detect a difference of $\delta=(0.05) \bar{Y}_{0}$ between a group mean and the overal1 mean for a confidence level of $95 \%$ and a probability of 0.05 of failing to detect such a difference. It is assumed that the variance $\left(\sigma^{2}\right)$ of the TLD response, determined in 8.1.1, does not vary with absorbed-dose rate. Calculate the following parameter:

$$
d=\frac{\delta}{\sqrt{2 \sigma^{2}}}=\frac{\delta}{\sigma \sqrt{2}}
$$

Then the sample size, $n$, required for each $x$ group to satisfy the above parameters is read off the graph of $n$ vs. d (Fig. A4.1) in Appendix A4. 
8.3.4 Example of sample number determination.

$$
\text { If } \begin{aligned}
\sigma= & 0.03 \bar{Y}_{0} \text { (determined in 8.1.1), } \\
d & =\frac{0.05 \bar{Y}_{0}}{\sqrt{2} 0.03 \bar{Y}_{0}}=1.18 .
\end{aligned}
$$

From Fig. A4.1, the sample size required is $n=4.4$. The sample size should be 5 , obtained by rounding up to the nearest integer.

NOTE 3 - One method by which this test requirement can be carried out is by comparing the TLD responses with the response of another radiation dosimeter whose absorbed-dose-rate dependence is known. A suitable type of dosimeter for use in most cases would be a calorimeter whose response is absorbed-dose-rate independent and whose radiation absorption properties are similar to the TLD under test.

\subsection{Dependence of TLD response on energy}

8.4.1 The radiation absorption properties of the TLDs employed in radiation-hardness testing should be similar to those of the material in which the dose is to be estimated. Calculations can be made to determine the effects of a broad incident energy spectrum on the response of the TLDs compared to that of the material of interest (usually silicon). The requirements of 7.5 are not applicable to this section.
8.4 .2
If the ratios
$\frac{\left(\mu_{\mathrm{en}} / \rho\right)_{\text {TLD }}}{\left(\mu_{\mathrm{en}} / \rho\right)_{\text {mat }}}$ and
$\frac{(S / \rho)_{\text {TLD }}}{(S / \rho)_{\text {mat }}}$
are equal to 1.0

within $\pm 10 \%$ over a significant range of the energy spectrum (for both calibration and test irradiations) incident upon both the TLD and the material of interest, then the energy-response performance of the TLD system is acceptable. Here, $\mu_{\mathrm{en}} / \rho$ is the mass photon energy absorption 
coefficient and $S / p$ is the mass collision electron stopping power. Tables of values of $\mu_{\mathrm{en}} / \rho$ and $S / \rho$ for several materials may be found in Appendix A2. The phrase "significant range of the energy spectrum" means the minimum and maximum energy limits containing those incident radiation particles (either photons or electrons) that contribute at least $90 \%$ of the absorbed dose. In this case, detailed energy spectral information is not required; the incident particle fluence (either photons or electrons) between the energy limits is sufficient.

8.4.3 If the energy spectrum of the radiation incident upon the TLD (under both calibration and test conditions) and the material of interest (under test conditions) is well known, then the conversion from absorbed dose in the TLD to absorbed dose in the material of interest can be calculated from such data. If this conversion can be made to an uncertainty of $\pm 10 \%$ or less, then the performance of the TLD system is acceptable. In this case, the criteria concerning the ratios of $\mu_{\mathrm{en}} / \rho$ and $S / \rho$ in 8.4.2 need not be met. (See ASTM Method E 666 for more specific guidelines.)

\subsection{Dependence of TLD response on direction of incident radiation.}

8.5.1 If the geometrical orientation of the TLD with respect to the radiation-hardness test field is significantly different than its orientation with respect to the calibration radiation field, then any dependency of the TLD response on the direction of the incident radiation should be determined. Select a number of TLDs from a batch meeting the requirements of 8.1 .1 . Divide the TLDs into a number of groups, $x$, each group containing $n$ samples. Prepare the TLDs in an identical manner, and irradiate each group to the same absorbed-dose level in the following manner: (a) group $g_{0}$ in the usually oriented direction used for routine calibration, and (b) groups $g_{1}, g_{2}, \ldots, g_{x}$ oriented, respectively, at 
angles $\theta_{1}, \theta_{2}, \ldots, \theta_{x}$, relative to the usually oriented direction with the center of the group at the same distance from the source. These angles should divide, in equal intervals of no more than $30^{\circ}$ each, the angle between normal and the maximum possible angle of incidence of the radiation-hardness test field. Read out a11 the TLDs. Determine the mean response, $\bar{Y}_{i}$, for each $x$ group of $n$ samples. Then the absolute difference between the mean, $\bar{Y}_{0}$, for the normally used calibration orientation and the mean for any other orientation should not exceed $5 \%$ of the mean. $\bar{Y}_{0}$. That is,

$$
\left|\bar{Y}_{i}-\bar{Y}_{0}\right| \leq 0.05 \bar{Y}_{0} \text {. }
$$

To determine the sample size $n$ required for each $x$ group, use the procedures of 8.3 .3 .

NOTE 4: CAUTION - This test applies only to a collimated-beam type calibration source geometry. If the angle of incidence of the radiation from the calibration source is nearly isotropic, then it is recommended that the TLDs and their encapsulation material should be as nearly spherical as possible.

\subsection{Dependence of TLD response on time between preparation and irradiation}

8.6.1 A change in TLD sensitivity can occur during the storage period between preparation and irradiation. This may be a significant effect if a wide range of storage periods is used. Use the following procedure to test for this effect. From a TLD batch meeting the requirements of 8.1.1, select two equal groups of $n$ samples each. Prepare the first group of TLDs and place them in the storage facility 
for a time interval equal to the maximum time interval expected between preparation and irradiation during routine application in either calibration or hardness testing. At a later time, prepare the second group of TLDs, and place them in the storage facility for the minimum time interval expected between preparation and irradiation. Time the procedures so that the ends of the storage periods for both groups occur simultaneously. Then irradiate both groups to the same absorbed dose level in the calibration facility and read them all out.

The difference between the mean TLD response, $\bar{Y}_{1}$, of the first group and the mean response, $\bar{Y}_{2}$, of the second group is a measure of the effect of storage time between preparation and irradiation. This difference should not exceed $20 \%$ of the average of the means of the two groups. That is,

$$
\left|\bar{Y}_{1}-\bar{Y}_{2}\right| \leq(0.2) \frac{\bar{Y}_{1}+\bar{Y}_{2}}{2} \text {. }
$$

8.6.2 If the effect tested for in 8.6.1 exceeds $5 \%$ of the average of the group means, then the functional dependence of the TLD response on the storage period should be determined in order that appropriate correction factors may be applied. This functional dependence may be determined by the procedures that follow.

8.6.3. The range of the elapsed time intervals between preparation and irradiation of interest is determined from the minimum and maximum intervals utilized in 8.6.1. Tests should be performed at a minimum of two intervals per decade of elapsed time over the entire range. For example, if the minimum elapsed time is 0.1 hour and maximum elapsed time is 100 hours, than an appropriate set of tests would be at elapsed times of $0.1,0.3,1,3,10,30$, and 100 hours. From a TLD batch meeting the requirements of 8.1 .1 , select as many groups of $n$ samples each as 
there are elapsed time intervals as determined above. Prepare a group of TLDs, and place it in the storage facility for the appropriate preselected test-time interval. Repeat this procedure for all preselected storage time intervals from the maximum to the minimum elapsed time. Arrange the storage times so that the ends of all procedures occur simultaneously. Then irradiate all groups to the same dose level in the calibration facility and read them all out as quickly as possible thereafter. This procedure is designed to minimize effects on dosimeter response caused by fading and variation in reader output. Determine the mean response for each group of TLDs. A plot of mean TLD response vs. elapsed time provides a correction factor for a change in TLD sensitivity as a function of storage period. The number of samples $n$ required for each group of TLDs should be determined by the procedures of 8.3.3.

\subsection{Dependence of TLD response on time between irradiation and readout}

8.7.1 Significant fading of the TLD response may occur during the storage period between the end of irradiation and readout. Use the following procedure to test for this effect. From a TLD batch meeting the requirements of 8.1 .1 , select two equal groups of $n$ samples each. Prepare the first group of TLDs, irradiate them in the calibration facility to a specific dose level, then place them in the storage facility for an interval equal to the maximum time interval.expected during routine application (for either calibration or hardness testing) between the end of the irradiation period and readout. Prepare the second group of TLDs, irradiate them in the calibration facility to the same dose level as the 
first group, then place them in the storage facility for an interval equal to the minimum time interval expected between the end of irradiation and readout. Time the procedures so the ends of the storage periods for both groups occur simultaneously. Read out all of the TLDs. The absolute difference between the mean TLD response, $\bar{Y}_{1}$, of the first group and the mean response, $\bar{\gamma}_{2}$, of the second group is a measure of the effect of storage time between the end of irradiation and readout. This difference should not exceed $20 \%$ of the average of the means of the two groups. That is,

$$
\left|\bar{Y}_{1}-\bar{Y}_{2}\right| \leq(0.2) \frac{\bar{Y}_{1}+\bar{Y}_{2}}{2}
$$

8.7.2 If the fading effect is greater than $(0.05) \frac{\bar{\gamma}_{1}+\bar{Y}_{2}}{2}$, then either a correction should be made to the TLD response or a procedure used that eliminates the need for a correction. A procedure that achieves the latter would be one in which all TLDs are read out at the same elapsed time after the end of irradiation. Such a procedure is often inconvenient or impractical. Therefore, it is usually necessary to apply a fading correction to the TLD response. The fading characteristics of the TLD system may be determined by the test procedures that follow.

8.7.3 Determine the minimum and maximum elapsed times between the end of the irradiation period and readout. Tests should be performed at a minimum of two time intervals per decade of elapsed time over the entire period as discussed in 8.6.3. From a TLD batch meeting the requirements of 8.1 .1 , select as many groups of $n$ samples each as there are elapsed time intervals as determined above. Each group of TLDs should undergo identical preparation and then should be irradiated in the 
calibration facility to the same dose level. The groups of TLDs are placed in the storage facility for all preselected appropriate time intervals from the maximum to the minimum elapsed time. Arrange the time of irradiations for all the groups so that the ends of their storage periods occur simultaneously. Read out all the TLDs. Determine the mean response for each group of TLDs. A plot of mean TLD response vs. elapsed time provides the fading correction factor. The number of samples $n$ required for each group of TLDs should be determined by the procedures of 8.3.3.

\subsection{Dependence of TLD response on temperature during storage or}

\section{irradiation}

8.8.1 If the storage temperature experienced by the TLDs between preparation and irradiation during routine radiation-hardness testing differs from the temperature during routine calibration by more than $10^{\circ} \mathrm{C}$, test 8.6 should be repeated over the range of temperatures expected using the environmental chamber instead of the storage facility. The performance criteria of 8.6 are applicable to this section.

8.8.2 If the storage temperature experienced by the TLDs between irradiation and readout during routine radiation-hardness testing differs from the temperature during routine calibration by more than $10^{\circ} \mathrm{C}$, test 8.7 should be repeated over the range of temperatures expected using the environmental chamber instead of the storage facility. The performance criteria of 8.7 are applicable to this section.

8.8.3 If the temperature experienced by the TLDs during the irradiation period during routine radiation-hardness testing differs from the temperature during routine calibration by more than $10^{\circ} \mathrm{C}$, then the effect on TLD response should be determined by the following procedure. Select a number of TLDs from a batch meeting the requirements of 8.1 .1 , 
prepare them in an identical manner, and separate them into two equal groups of $n$ samples each. Irradiate the first group in the calibration facility to a specific dose level, maintaining the temperature of the TLDs at the minimum temperature expected during routine hardness-test irradiations. Irradiate the second group in the calibration facility to the same dose level, maintaining the temperature of the TLDs at the maximum temperature expected during routine hardness-test irradiations. Readout all of the TLDs. The difference between the mean TLD response, $\bar{Y}_{1}$, of the first group and the mean response, $\bar{Y}_{2}$, of the second group is a measure of the effect of temperature variation during irradiation. This difference should not exceed $20 \%$ of the average of the means of the two groups. If the magnitude of the effect is greater than $5 \%$ of the average of the means, then appropriate corrections to the TLD responses should be determined by procedures analogous to those used in 8.6.

\subsection{Dependence of TLD response on humidity}

8.9.1 In general, the responses of the most widely used TLDs have not been shown to be sensitive to changes in relative humidity [3]. However, if a TLD that is hygroscopic (such as lithium borate) is being considered for application in radiation-hardness testing, then the perfomance tests of 8.8 should be repeated with the humidity as the variable parameter and the temperature maintained at the maximum value used in the temperature tests.

NOTE 5. Once a TLD system of a particular TL phosphor type and physical configuration has met the performance requirements of Section 8 , new batches of the same type need only be tested for the requirements of 8.1 (batch uniformity). 


\section{Calibration of the TLD system}

9.1 Calibrate the TLD system in a manner such that the TLD response can be related directly to the absorbed dose in the TLD phosphor. Use a suitable, well-characterized radiation source in the calibration. Radioactive isotope sources such as ${ }^{60} \mathrm{Co}$ or ${ }^{137} \mathrm{Cs}$ are generally used for this purpose. The exposure rate (or absorbed-dose rate) produced by the source should be known to better than $\pm 5 \%$ at all locations normally used for calibration irradiations. The methods used for determining the output rates of such sources include the use of secondary standard radiation measuring instruments, such as air-ionization chambers, whose calibration is traceable to the National Bureau of Standards or other recognized calibration laboratories. Other types of dosimeters, whose responses are absolute (require no calibration), such as ferrous sulfate dosimeters and calorimeters, may also be employed for source calibration.

\subsection{The response of most types of TLDs generally is not linear} as a function of absorbed dose [4]. The response of a typical TLD is usually linear from low absorbed-dose levels (millirad region) to approximately 10 Gy $\left(10^{3} \mathrm{rad}\right)$, then becomes supralinear up to approximately $10^{2}-$ $10^{3}$ Gy $\left(10^{4}-10^{5} \mathrm{rad}\right)$ where saturation effects become evident. Exercise care in the use of the TLD system for absorbed dose levels of approximately $10^{3}$ Gy $\left(10^{5} \mathrm{rad}\right)$ or higher to ensure that the change in the system response per unit absorbed dose is adequate in order that the absorbed dose can be determined within the required uncertainty.

9.3 The absorbed-dose range of calibration should cover the maximum absorbed-dose range of interest for the intended application. Measure a minimum of three absorbed-dose levels per decade of absorbed dose covered. Since the TLD response vs. absorbed dose for most types of TLDs generally is 
not linear, make a sufficient number of measurements at each absorbeddose level to define accurately the shape of the characteristic response curve. The number of TLD samples required to determine the mean response at each absorbed-dose level is given by the following procedures.

9.3.1 In order to determine the mean TLD response, $\bar{Y}_{0}$, within $\pm 5 \%$ at a $95 \%$ confidence level, the number of TLD samples required for a given absorbed-dose level is

$$
n=\frac{(2.045)^{2} \mathrm{~s}^{2}}{\left(0.05 \bar{\gamma}_{0}\right)^{2}} \text {, }
$$

where $s$ is the estimate of the standard deviation, $\sigma$, of the TLD response distribution as determined by the procedures of 8.1.1. For example, if $s=(0.06) \bar{Y}_{0}$, then

$$
n=\frac{(2.045)^{2}\left(0.06 \bar{Y}_{0}\right)^{2}}{\left(0.05 \bar{Y}_{0}\right)^{2}}=6.0
$$

(See Section 2-3.2 of reference 2 for more details.)

9.3.2 The procedures described in 9.3.1 assume that the standard deviation of the TLD response distribution is constant for all absorbed-dose levels measured. This assumption generally is valid over most of the usable absorbed-dose range for most TLDs but may not be correct for very high absorbed-dose levels of approximately $10^{3}$ Gy $\left(10^{5} \mathrm{rad}\right)$ or higher. If the TLD system is used at these absorbed-dose levels, then redetermine the standard deviation of the response distribution at these levels by repeating the procedures of 8.1 .1 .

9.4 During a calibration irradiation, encapsulate the TL phosphor in a material with a thickness just sufficient to produce electron equili- 
brium in the phosphor (see Appendix A3). If possible, the encapsulation material should have the same thickness on all sides of the dosimeter.

NOTE 6 . The encapsulation material should resemble the phosphor material as closely as possible with respect to radiation absorption properties. For example, if the $\mathrm{TL}$ phosphor is $\mathrm{CaF}_{2}$, acceptable encapsulation material would be $\mathrm{CaF}_{2}, \mathrm{Al}$, or $\mathrm{Si}$. If the calibration source is ${ }^{60} \mathrm{Co}$, then a thickness of $2.2 \mathrm{~mm}$ of $\mathrm{Al}$ (equal to the practical range of the highest energy secondary electrons produced) would establish electron equilibrium in the $\mathrm{CaF}_{2}$ phosphor. This thickness is sufficient to stop secondary electrons that might be generated by the source photons in material other than the encapsulation material.

9.5 It is necessary to correct for attenuation of the photons from the source by the layer of material used to establish electron equilibrium. This should be done using the following formula:

$$
X=x_{0} e^{\left[-\left(\mu_{e n} / \rho\right) \rho x\right]}
$$

where $X$ is the attenuated exposure at the position of the TLD phosphor in roentgens,

$x_{0}$ is the unattenuated exposure in roentgens,

$\mu_{e n} / \rho$ is the mass energy absorption coefficient of the encapsulation material for the effective source photon energy in $\mathrm{cm}^{2} / \mathrm{g}$,

$\rho$ is the density of the encapsulation material in $\mathrm{g} / \mathrm{cm}^{3}$, and

$x$ is the thickness of the encapsulation material in $\mathrm{cm}$.

Values of $\left(\mu_{\mathrm{en}} / \rho\right)$ may be found in Appendix A2. 
NOTE 7. The attenuation formula given is not rigorously correct for a broad-beam geometry as it does not include a buildup factor. Buildup factors generally are not available for a wide range of energies, materials, and geometries. However, the formula gives results that are in reasonable agreement with more rigorous treatments for materials of low to medium atomic number of relatively thin sections over the range of photon energies that are applicable to this standard.

9.6 Once the exposure has been determined, the absorbed dose (in Gy) to the encapsulated TL phosphor is found from the formula:

$$
D_{\text {TLD }}=\frac{\left(\mu_{e n} / \rho\right)_{\text {TLD }}}{\left(\mu_{e n} / \rho\right)_{\text {air }}}\left(0.869 \times 10^{-2}\right) x
$$

The factor $\left(0.869 \times 10^{-2}\right)$ is used to convert exposure $(R)$ to absorbed dose in air (Gy). Conversion of exposure ( $R$ ) to absorbed dose in air (rad) would require a factor of 0.869 . The subscripts refer to the material of interest. As in 9.5, the $\mu_{\mathrm{en}} / \rho$ values are evaluated at the effective calibration source photon energy. This formula is valid only if electron equilibrium exists in the TL phosphor. It is assumed that the incident photon fluence is essentially monoenergetic. If this is not the case, then average all of the energy-dependent energy absorption coefficients of 9.5 and 9.6 over the appropriate energy spectrum.

9.7 The absorbed dose calibration results of the procedures of 9.3 to 9.6 are valid only for a given batch of TLDs. A different batch generally will have a different radiation sensitivity. However, this difference is usually a constant factor over the entire absorbed-dose 
range. Therefore, it is usually not necessary to generate a new calibration curve over the entire absorbed-dose range covered. Measurements at a minimum of two points in the linear region and at a minimum of three points in the supralinear and saturation regions of the response curve normally is adequate to characterize the absorbed-dose sensitivity of a different batch.

9.8 Because of possible long term aging effects in the TLD reader, recalibrate the TLD system (as specified in 9.3 to 9.6) at periodic intervals over the entire absorbed-dose range of application. The time interval between calibrations depends on the long-term stability of the TLD reader and on how much it is used. If the reader is used only a few hours a week, then recalibration at 6 or 12 months intervals should be adequate. For a reader that is used daily with a heavy work load, monthly calibration is probably required. 
10. Procedures for characterizing and monitoring a test radiation field with TLD systems

10.1 A variety of sources are used to produce the radiation fields that are appropriate for radiation-hardness testing of electronic devices. The most widely used fields are ${ }^{60}$ Co gamma rays, $x$-ray (bremsstrahlung) photons from fast-pulse (flash) accelerators, and high-energy electron beams from linear accelerators (1 inacs). Maximum absorbed-dose rates range from about $10 \mathrm{~Gy}(\mathrm{Si}) / \mathrm{s}\left(10^{3} \mathrm{rad}(\mathrm{Si}) / \mathrm{s}\right)$ to about $10^{10} \mathrm{~Gy}(\mathrm{Si}) / \mathrm{s}$ $\left(10^{12} \mathrm{rad}(\mathrm{Si}) / \mathrm{s}\right)$.

10.2 TLDs irradiated in various locations in the test facility under free-field conditions can be used to characterize the radiation field. In addition, it may be desirable and practical to monitor the radiation field of the source during actual radiation-hardness testing of electronic devices. When there is a significant variation of the source output from irradiation to irradiation, use TLDs as monitors.

10.2.1 For irradiation by gamma rays' or pulsed $x$ rays, encapsulate the $T L$ phosphor in material with sufficient thickness to produce electron equilibrium conditions in the TL phosphor. See Section 9.4 and Appendix A3 for details. The equilibrium material should have radiation absorption properties similar to the material in which the absorbed dose is to be determined. Since silicon is usually the material of interest, aluminum is an acceptable equilibrium material.

10.2.2 For irradiation with electrons, the absorbed dose as a function of depth for normally incident monoenergetic electrons has the characteristic shape shown in Fig. 1 [5]. For the electron energy spectrum appropriate to the test source being employed, encapsulate the TL phosphor 
in a material with a thickness of approximately 0.1 the practical range $\left(R_{p}\right.$ in Fig. 1) of the maximum-energy electrons on the incident radiation side and with a thickness greater than the practical range on the side opposite the incident electrons. By placing the TLD at this depth in the material, possibly anomalous response caused by interface effects at the material surface is avoided. As in the case for photons, the encapsulation material should have radiation absorption properties similar to the material of interest. In all cases in which the TLD is encapsulated, the combined thickness of the encapsulation material in front of the TLD and the TLD itself should be such that the back surface of the TLD is located at a depth not much greater than the peak of the absorbed dose vs. depth curve. For normal incidence, this depth is approximately one half of the practical range of the electrons.

10.3 Select the TLDs to be used in characterizing or monitoring the test radiation field from a batch that has been calibrated previously. From the same batch, select several TLDs to be used as calibrationcheck TLDs. The number of TLDs required for determining a specific absorbed dose during the test irradiation may be obtained from the procedures of 9.3 .

10.3.1 At a time as close as possible to that of the hardnesstesting irradiations, irradiate several TLDs in the calibration facility to two or more absorbed-dose levels within the absorbed-dose range expected for the test irradiations. Read out these calibrated TLDs along with the TLDs used in the hardness-testing irradiations. These calibrated TLDs serve as checks on the stability of the TLD system.

10.3.2 If it is not convenient to use the procedure described in 10.3.1, an alternate procedure may be used. At some time before the 
hardness-testing irradiations occur, irradiate a number of TLDs that will be used as calibration checks in the calibration facility to two or more absorbed-dose levels within the expected absorbed-dose range of the test irradiations. Place these calibrated TLDs in the storage facility until hardness-testing irradiations are performed. Remove a few calibrated TLDs from storage and read them out along with the test TLDs. The other calibrated TLDs remain in storage until the next test irradiations are performed, when a few more should be read out with the test TLDs. The disadvantage of this method compared to that of 10.3.1, is that different fading (and possibly temperature dependence) corrections must be applied to each group of calibrated TLDs; in addition, the fading correction is different for the calibrated TLDs than for the test TLDs. If the fading correction is excessively large $(>25 \%)$ for the calibrated TLDs, calibrate another group for readout with the test-irradiated TLDs.

10.3.3 If reusable TLDs are irradiated (for either calibration or testing) to high single or accumulated absorbed-dose levels ( $>10^{2} \mathrm{~Gy}$ $\left.\left(10^{4} \mathrm{rad}\right)\right)$, recalibration may be required after each anneal-irradiation cycle because of possible changes in absorbed-dose sensitivity [6]. If the TLD system being used is subject to this effect, it is recommended that each TLD in the batch be irradiated only once until the entire batch has been used, after which the entire batch can be annealed and a new calibration performed. In addition, because of possible changes in batch response uniformity due to high absorbed-dose irradiations, repeat the tests of 8.1.1 periodically.

10.4 The equilibrium absorbed dose in a material of interest can be estimated from the absorbed dose in a TLD exposed to the same radiation 
field. This involves a conversion of the absorbed dose in a TLD irradiated within a material under electron equilibrium conditions to absorbed dose in a volume element of the material of interest having comparable dimensions to the TLD, the volume element being surrounded by an equilibrium thickness of the same material of interest. It has been shown that the TLD response per unit absorbed dose in the TLD material is independent of the type (photons or electrons) or the energy spectrum of the incident radiation for the range of energies considered in this standard.

10.4.1 In a material undergoing photon irradiation, the presence of the TLD may perturb the spectrum of the secondary electrons generated by the primary photons. If the TLD is very thin compared to the range of the secondary electrons, most of the energy deposited in the TLD and in the material surrounding it come from secondary electrons produced outside the TLD (i.e., in the equilibrium layer of material). Thus, the absorbed dose in the material is given by

$$
D_{\text {mat. }}=\frac{(S / \rho)_{\text {mat. }}}{(S / \rho)_{\text {TLD }}} \cdot D_{\text {TLD }}
$$

If the TLD has a thickness much greater than the range of the secondary electrons, most of the energy deposited in it comes from secondary electrons produced within the TLD itself. Thus, the absorbed dose in the material is given by

$$
D_{\text {mat. }}=\frac{\left(\mu_{\mathrm{en}} / \rho\right)_{\text {mat. }}}{\left(\mu_{\text {en }} / \rho\right)_{\text {TLD }}} \cdot D_{\text {TLD }}
$$

If the TLD thickness is intermediate between the two limits given above, then the two equations may be combined with appropriate weighting factors to reflect the relative contributions of each term [7]. In 
general, for low atomic number material and for photon energies above about $0.2 \mathrm{MeV}$, the difference in the absorbed dose determined by equations (1) and (2) is usually less than 10\%. If the equilibrium buildup material surrounding the TLD is not silicon, then the equilibrium absorbed dose in silicon is given by

$$
D_{S i}=\frac{\left(\mu_{e n} / \rho\right)_{S i}}{\left(\mu_{e n} / \rho\right)_{m a t}} \cdot D_{\text {mat. }} \text {. }
$$

10.4.2 The effects of dosimeter size on the absorbed-dose conversion for electron irradiation are not as clearly understood as for photon irradiation $[8,9]$. However, reasonable estimates of the absorbed dose in the material of interest can be made using equation (1) in 10.4.1 if the initial incident electron energy is greater than $5 \mathrm{MeV}$ and the TLD is less than two thirds of the practical electron range in thickness. If the material surrounding the TLD is not silicon, then the absorbed dose in silicon is given by

$$
D_{S i}=\frac{(S / \rho)_{S i}}{(S / \rho)_{\text {mat. }}} \cdot D_{\text {mat. }} \text {. }
$$

10.5 Limitations of interpretation. Caution must be used in interpreting the results of using the procedures of 10.4 for converting the absorbed dose in the TLD to absorbed dose in the material of interest (assumed to be silicon). Reasons for this are given in the following sections.

10.5.1 The absorbed-dose conversions are most reliable when the TLD and the equilibrium material surrounding it are similar to silicon in radiation absorption properties.

10.5.2 The absorbed dose in the material is interpreted from an integrated or average absorbed dose in the TLD at its location in the 
surrounding material and does not necessarily represent the actual absorbed dose at any other point within the volume of the material.

10.5.3 The evaluated equilibrium absorbed dose in silicon does not necessarily represent the absorbed dose in an electronic device irradiated in the same test field. A number of factors complicate a straightforward interpretation of the absorbed dose distribution within an irradiated device. Examples of such perturbing factors include attenuation of the radiation by the packaging material surrounding the device chip, variations in absorbed dose near interfaces of the thin insulation and metallized layers on or near the front surface of the chip, and changes in radiation energy spectrum due to scattered radiation from adjacent hardware.

10.5.4 These absorbed dose interpretations are valid only if the ratios of the energy absorption coefficients and stopping powers of silicon relative to the TLD are fairly constant over a significant range of the incident photon or electron spectra. Otherwise, the incident energy spectra must be known and the uncertainty in the results of the absorbed dose conversion depends on the accuracy of the spectra data. 


\section{Report of results}

11.1 Reports of radiation-hardness testing of electronic devices should include information that fully describes the following:

11.1.1 The TLD system employed should be given, including the type and physical form of the TLDs, the type of TLD reader, and the annealing procedure used, if any.

11.1.2 The results of a11 performance tests carried out or reference to relevant published studies of the TLD system should be given. Such test results should include, as a minimum, the sample size, the mean value of the sample responses, the absorbed-dose level, and the standard deviation of the sample response distribution.

11.1.3 The procedure for calibrating the absorbed-dose response of the TLD system should be described, including the radiation source type, irradiation geometry, and conditions (e.g., absorbed-dose level, absorbeddose rate, and equilibrium material).

11.1.4 A description of the radiation-hardness-test irradiations should be given, including radiation source type, geometry, and conditions, (e.g., absorbed-dose leve1, absorbed-dose rate, and equilibrium material) as well as any useful supplemental data (e.g., energy spectra).

11.1.5 A description of the conversion of TLD response to absorbed dose in the material of interest should be given, including calibration factors, correction factors, and absorbed-dose conversion factors. The absorbed-dose conversion factors would include information such as the radiation absorption characteristics of the material of interest and assumptions or data about the source energy spectrum.

11.1.6 An estimate of the overall uncertainty of the results should be given as well as an error analysis of the factors contributing to the random and systematic uncertainties. (For an example, see A1.6 of Appendix A1.) 


\section{REFERENCES}

1. Roesch, W. C., and Attix, F. H., Basic Concepts of Dosimetry, Radiation Dosimetry, Vol. I, Second Edition, F. H. Attix, W. C. Roesch, and E. Tochilin, Eds., Academic Press, New York, pp. 2-41, 1968.

2. Natrella, M.G., Experimental Statistics, NBS Handbook 91, U.S. Government Printing Office, Washington, D.C. 20402, 1963.

3. Burgkhardt, B., Herrera, R., and Piesch, E., Fading Characteristics of Different Thermoluminescent Dosimeters, Nucl. Inst. Meth., Vol. 137, pp. 41-47, 1976.

4. Gorbics, S.G., and Attix, F.H., Thermoluminescent Dosimeters for High-Dose Application, Health Phys., Vol. 25, pp. 499-506, 1973.

5. Humphreys, J.C., Chappe11, S.E., McLaughlin, W.L., and Jarreti, R.D., Measurements of Dose Distributions in Various Materials Irradiated by 10-MeV Electrons, Radiat. Phys. Chem., Vol. 9, pp. 749-761, 1977.

6. Marrone, M.J. and Attix, F.H., Damage Effects in $\mathrm{CaF}_{2}: \mathrm{Mn}$ and LiF Thermol uminescent Dosimeters, Health Phys., Vol. 10, pp. 431-436, 1964.

7. Burlin, T. E., Cavity-Chamber Theory, Radiation Dosimetry, Vol. I, Second Edition, F. H. Attix, W. C. Roesch, and E. Tochilin, Eds., Academic Press, New York, pp. 332-392, 1968.

8. Paliwal, B.R. and Almond, P.R., Applications of Cavity Theories for Electrons to LiF Dosimeters, Phys. Med. Biol., Vol. 20, No. 4, pp. 547-558, 1975.

9. Holt, J.G., Edelstein, G.R., and Clark, T.E., Energy Dependence of the Response of Lithium Fluoride TLD Rods in High Energy Electron Fields, Phys. Pled. Biol., Vol. 20, No. 4, pp. 559-570, 1975. 
10. Cameron, J. R., Suntharalingam, N., and Kenney, G. N., Thermoluminescent Dosimetry, University of Wisconsin Press, Madison, Wisconsin, 1968.

11. Becker, K. Solid State Dosimetry, CRC Press, Cleveland, Ohio, 1973.

12. Fowler, J. F., and Attix, F. H., Solid State Integrating Dosimeters, Radiation Dosimetry, Vol. II, Second Edition, F. H. Attix, W. C. Roesch, and E. Tochilin, Eds., Academic Press, New York, pp. 269-290, 1966.

13. Storm, E., and Israel, H. I., Photon Cross Sections from $1 \mathrm{keV}$ to $100 \mathrm{MeV}$ for Elements $Z=1$ to $Z=100$, Nuc. Data Tables, Vol. 7, No. 6, Academic Press, New York, 1970.

14. Hubbe11, J. H., Photon Cross Sections, Attenuation Coefficients, and Energy Absorption Coefficients from $10 \mathrm{keV}$ to $100 \mathrm{GeV}$, Nat. Std. Ref. Data Ser., Nat. Bur. Std. 29, 1969.

15. Pages, L., Bertal, E., Joffre, H., and Sklavenitis, L., Energy Loss, Range, and Bremsstrahlung Vield for 10-keV to 100-MeV Electrons in Various Elements and Chemical Compounds, Atomic Data, Vol. 4, No. 1, Academic Press, New York, 1972.

16. Attix, F. H., Basic Y-ray Dosimetry, Health Phys., Vol. 15, pp. 49-56, 1968.

17. Sinclair, W. K., Radiobiological Dosimetry, Radiation Dosimetry, Vol. III, Second Edition, F. H. Attix and E. Tochilin, Eds., Academic Press, New York, pp. 617-676, 1969.

18. Whyte, G. N., Principles of Radiation Dosimetry, John Wiley \& Sons, New York, p. 62, 1959.

19. ICRU, Radiobiological Dosimetry, Report 10e, 1963.

20. Central Axis Depth Dose Data for Use in Radiotherapy, Brit. J. Radiol. Supp1. 11, M. Cohen, D. E. A. Jones, and D. Greene, Eds., British Institute of Radiology, London, 1972. 


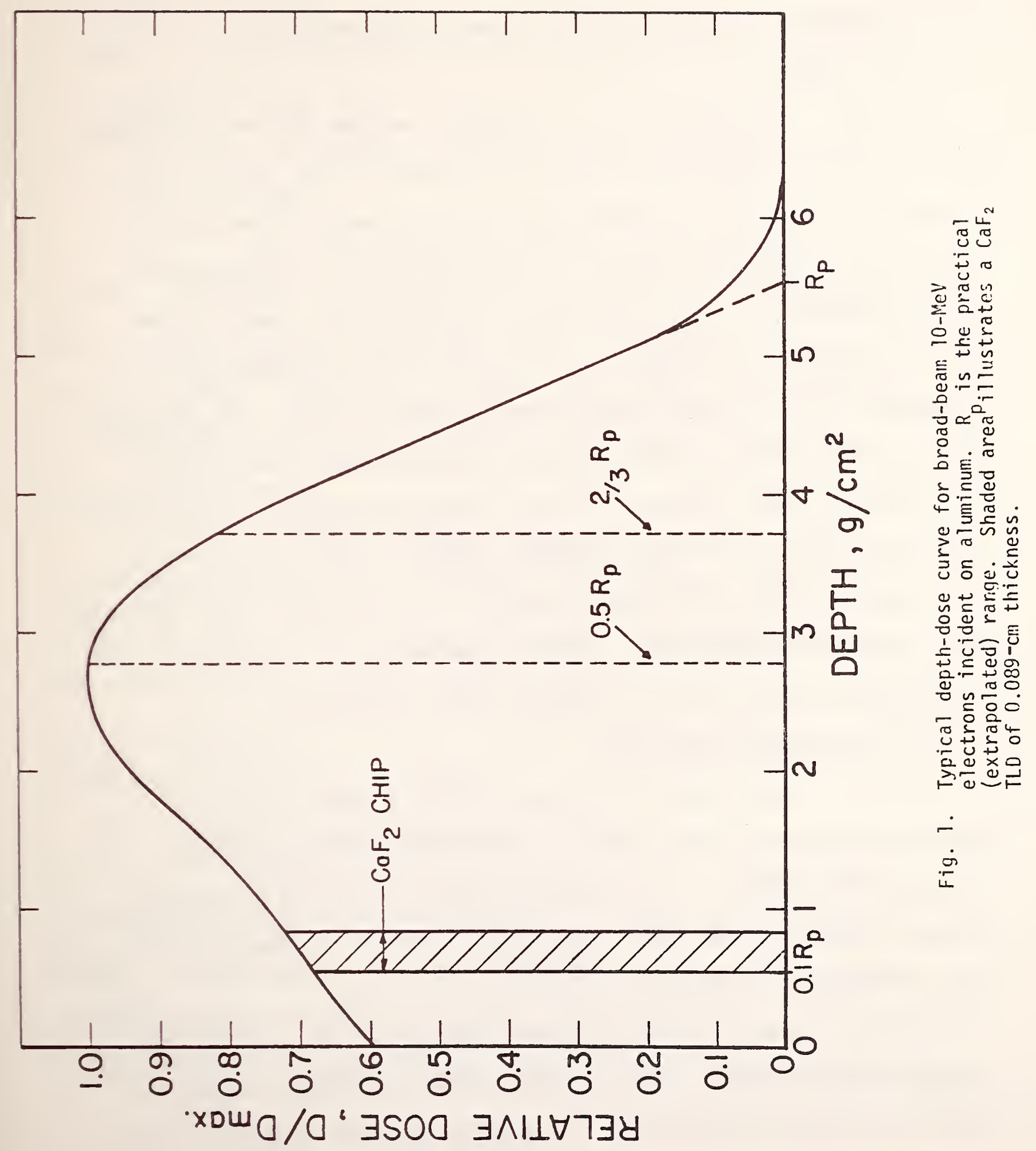




\section{APPENDIXES}

A7. Recommended Procedures for Application of $\mathrm{CaF}_{2}:$ Mn Chips

A7. 1 Scope

A1.1.1 The procedures in this Appendix address the use of manganese doped calcium fluoride TLDs in the form of reusable solid chips. This is done for illustrative purposes only and is not meant to imply that other types of phosphors, and physical forms of this or other phosphors, are not suitable for use in radiation-hardness testing. Each type and form of TLD requires a somewhat different application procedure. See references 10-12 for descriptions of various types of TLDs. $\mathrm{CaF}_{2}:$ Mn chips do have some significant advantages over some other types and forms of TLDs. Some of these advantages include radiation absorption characteristics reasonably similar to silicon, a simple annealing schedule (compared to Lif), ease of handling compared to powders, and relatively linear absorbeddose response characteristics. The only disadvantage in using $\mathrm{CaF}_{2}$ : Mn TLDs is a moderate fading of the TLD response after irradiation.

\section{A1.2 Dosimeter preparation}

A1.2.1 Always handle chips gently and in a manner that will minimize mechanical stress as well as the possibility of scratching or chipping the dosimeter. The recommended handling tool is a vacuum pen; however, tweezers may be used. The contact points of all handling tools should be coated with Teflon if possible.

A7.2.2 Keep the chips as clean as possible at all times so that cleaning can be avoided. Clean the chips only if absolutely necessary since the process can contribute to the aging (decrease in sensitivity) of the phosphor. If cleaning is necessary, the following procedure may be used: 
1. bathe the chips in cool trichloroethylene for about 10 minutes in an ultrasonic cleaner,

2. bathe the chips in distilled water for about 10 minutes in the ultrasonic cleaner, and

3. dry the chips as rapidly as possible (dry nitrogen may be used to hasten the drying).

A1.2.3 Anneal the chips for one hour at $500^{\circ} \mathrm{C}$ followed by rapid cooling. This annealing is essential after irradiation at high absorbed doses to avoid changes in dose sensitivity. For annealing, place the chips in a tray or container of a material that will not react with them at the annealing temperature. Platinum-plated silver or pyrex glass should be satisfactory.

A1.2.4 For photon irradiation, encapsulate the chips so as to provide electron equilibrium conditions in the dosimeter. See 9.4 and Appendix A3. The required thickness of material surrounding the chip is approximately equal to the range of the highest energy secondary electrons that are generated by the incident photons. See 10.2.2 for encapsulation of the chips for electron irradiation.

\section{A1.3 Effects of storage and transportation}

A1.3.1 Hinimize the storage and transportation of the dosimeters, either between preparation and irradiation or between irradiation and readout. The dosimeters should be protected from uv light and elevated temperatures during storage or transit as much as possible. Apply corrections for any effects on dosimeter response caused by the duration and conditions 
of the storage or transit periods, or both. Correction factors for fading during the storage periods before and after irradiation and for any temperature effects can be determined by the procedures of Section 8. Changes in humidity have not been shown to affect the response of $\mathrm{CaF}_{2}: \mathrm{Mn}$ chips.

\section{A1.4 Irradiation procedures}

Procedures for using the TLDs during calibration or test irradiations depend on conditions within each individual facility and on the requirements of the radiation-hardness tests. However, precautions on handling, exposure to light, and exposure to temperature variations apply. The procedures described in Sections 9 and 10 are applicable.

\section{A1.5 Readout}

A1.5.1 Pre-readout cleaning of the chips should be done only if necessary (see A7.2.2). Some types of TLDs, such as LiF, may require pre-readout annealing. This is not required for $\mathrm{CaF}_{2}: \mathrm{Mn}$.

A7.5.2 A heating rate of approximately $30^{\circ} \mathrm{C} / \mathrm{s}$ should be satisfactory. The TLD chips should have been heated to a temperature of at least $450^{\circ} \mathrm{C}$ and preferably to $500^{\circ} \mathrm{C}$ at the end of the heating cycle.

A1.5.3 In general, the preferred measure of the TLD response is the peak height of the light output vs. temperature curve. However, the integrated light output is usually more conveniently obtained and is satisfactory in most cases. When trade-offs are to be made with regard to efficiency and accuracy, experience with a particular dosimeter and reader combination usually determines which parameter gives the most satisfactory measure of TLD response. 
A1.5.4 Host TLD readers are furnished with some type of check light source that may be used to check the stability of the reader. This procedure provides a check of the reader stability only for the light measuring section and its associated electronics; it does not test the performance and stability of the heating and temperature measuring section. Therefore, the use of calibrated TLDs, as described in 10.3, during each readout session also is recommended.

\section{A7.6 Precision and accuracy}

A1.6.1 An example of the error analysis of a typical $\mathrm{CaF}_{2}: \mathrm{Mn}$ chip system employed in radiation-hardness testing is given in Tables A1.1 and A1.2. These tables identify the sources of error and give estimated magnitudes of the upper bounds of the errors. A basic assumption for these data is that the TLD system has been characterized and used in accordance with the recommended procedures in this standard. Therefore, as pointed out in a footnote in Table Al.1, certain potential sources of error are expected to be insignificant in this case.

A1.6.2 Table A1.1 lists systematic errors and Table Al.2 lists random errors. The systematic errors are estimates of the upper Timits of the errors for the particular factors identified. Since, by their very nature, systematic errors cannot be known with great accuracy, they are estimated from observation of the long-term behavior of a given TLD system. On the other hand, random errors are obtained by standard statistical techniques. The values given in Table Al.2 are equal to one standard deviation $(\sigma)$ of a batch or individual TLD response distribution.

A7.6.3 A further distinction is made in the analysis between whether the absorbed dose is determined from a TLD system utilizing dosimeters in an individual mode or in a batch mode. The difference between individual and batch mode is discussed in Section 8 . 
A1.6.4 A universally accepted procedure for combining systematic errors does not exist. Generally, these errors are combined either by simple addition or by a combination in quadrature (i.e., the square root of the sum of the squares). In this analysis, the systematic errors in Table A1.1 are combined in quadrature and the result is given as the total systematic uncertainty, $E_{S}$. Whatever method of combining errors is used should always be reported in the radiationhardness test results.

A1.6.5 The random errors listed in Table A1.2 are combined in quadrature and the result given as a value of $\sigma_{\mathrm{T}}$. For the purposes of this analysis, five dosimeters are assumed to be used in a specific radiation hardness test. In this case, a standard error of the mean (SEOM) of the absorbed-dose response of the five dosimeters is found by dividing the combined standard deviation, $\sigma_{T}$, by the square root of the number, $n$, of dosimeters employed; that is

$$
\operatorname{SEOM}=\frac{\sigma_{T}}{\sqrt{n}}
$$

The total random uncertainty is taken to be equal to three times the SEOM.

A1.6.6 The overall uncertainty of the mean absorbed dose determined by five dosimeters for the conditions described is taken as the algebraic sum of the total systematic uncertainty, $E_{S}$, and the total random uncertainty, $E_{R}$. For this example, the overall uncertainty is equal to the following:

(for individual dosimeters), $E_{S}+E_{R}=6.7 \%$

(for batch), $E_{S}+E_{R}=13 \%$ 
Estimates of Systematic Uncertainties for Typical $\mathrm{CaF}_{2}: \mathrm{Mn}$ Chip System

\section{Source of \\ Systematic Error}

1. ${ }^{60}$ Co source calibration

2. TLD absorbed dose calibration

a. Determination of calibration curve

b. Conversion of exposure to dose in TLD

3. Time between irradiation and readout: fading correction factor

4. Conversion of dose in TLD to dose in Si for device test irradiation

5. Correction for attenuation in equilibrium material

6. Absorbed dose rate dependence

7. Energy dependence

8. Time between preparation and readout

9. Directional dependence

10. Temperature before, during, and after irradiation

11. Humidity dependence

12. Effect of size of TLD
Individual

Dosimeters Batch

$3 \%$

$3 \%$

$1 \%$

$2 \%$

$2 \%$

$2 \%$

$1 \%$

$3 \%$

$2 \%$

$2 \%$

$2 \%$

$2 \%$

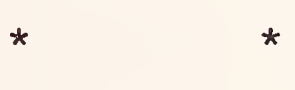

* $\quad$ *

* $\quad$ *

* $\quad *$

* $\quad$ *

* $\quad$ *

* $\quad$ *

Total systematic uncertainty, all errors combined in quadrature, $E_{S}$

* For purposes of this error analysis, it is assumed that the TLD system is utilized in such a way as to make these errors negligible. However, this assumption is not valid under all conditions of radiation-hardness testing. A careful examination of all possible sources of error must be made for the irradiation conditions and TLD system employed in each specific test. 
Table A1.2

Estimates of Random Uncertainties for Typical $\mathrm{CaF}_{2}:$ Mn Chip System

Sources of

Random Error
Individual

Dosimeters

Batch

1. Reproducibility of individual dosimeter response, $\sigma \quad 1 \%$

2. Correction for sensitivity variation between dosimeters, $\sigma$

$1 \%$

3. Uniformity of batch response, $\sigma$

Tota1, combined in quadrature, $\sigma_{\mathrm{T}}$

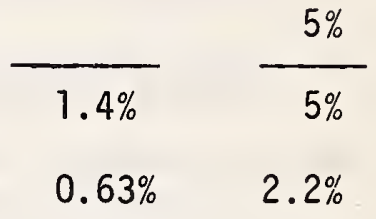

Standard error of mean of dose response of five dosimeters, $\sigma_{T} / \sqrt{n}$

Total random uncertainty, $E_{R}=3\left(\sigma_{T} / \sqrt{n}\right)$

$1.9 \%$

$0.7 \%$ 
A2. Energy Absorption Coefficients and Collision Stopping Powers

A2.1 Values of photon mass energy absorption coefficients and electron mass collision stopping powers for several materials of interest in radiation-hardness testing are shown in Table A2.1. All values for the energy absorption coefficients are derived from reference 13, except those values for air that are from reference 14. Values for the stopping powers are from reference 15. Energy absorption coefficient values for chemical compounds not listed directly were evaluated from the coefficients $\mu_{j} / \rho_{j}$ for the constituent elements according to the weighted average

$$
\mu / \rho=\sum_{i} w_{i}\left(\mu_{i} / \rho_{i}\right)
$$

where $w_{j}$ is the proportion by weight of the $i$-th constituent [14]. Ratios of the energy absorption coefficients for the various materials in Table A2.1 relative to silicon as a function of incident photon energy are shown in Figure A2.1. Similarly, ratios of stopping powers are shown in Figure A2.2. 
Table A2.1. Mass Energy Absorption Coefficients: $\mu_{\mathrm{en}} / \rho\left(\mathrm{cm}^{2} / \mathrm{g}\right)$ and Mass Collision Stopping Powers: $S / \rho\left(\mathrm{MeV} \cdot \mathrm{cm}^{2} / \mathrm{g}\right)$

\begin{tabular}{|c|c|c|c|c|c|c|c|c|c|c|}
\hline \multirow{2}{*}{$\begin{array}{l}\text { Energy } \\
\text { (MeV) }\end{array}$} & \multicolumn{2}{|c|}{ Air } & \multicolumn{2}{|c|}{ LiF } & \multicolumn{2}{|c|}{$\mathrm{CaF}_{2}$} & \multicolumn{2}{|c|}{ Al } & \multicolumn{2}{|c|}{$\mathrm{Si}$} \\
\hline & $\mu_{\text {en }} / \rho$ & $S / \rho$ & $\mu_{e n} / \rho$ & $S / \rho$ & $\mu_{\mathrm{en}} / \rho$ & $S / \rho$ & $\mu_{\text {en }} / \rho$ & $S / 0$ & $\mu_{\text {en }} / \rho$ & $S / \rho$ \\
\hline 0.01 & 4.61 & 19.7 & 5.74 & 18.2 & 48.3 & 16.6 & 25.4 & 16.4 & 32.4 & 16.9 \\
\hline 0.02 & 0.511 & 11.5 & 0.632 & 10.7 & 6.58 & 9.93 & 3.06 & 9.79 & 3.99 & 10.1 \\
\hline 0.04 & 0.0669 & 6.83 & 0.0769 & 6.31 & 0.819 & 5.96 & 0.353 & 5.88 & 0.470 & 6.07 \\
\hline 0.06 & 0.0305 & 5.10 & 0.0317 & 4.71 & 0.247 & 4.48 & 0.108 & 4.42 & 0.142 & 4.56 \\
\hline 0.08 & 0.0243 & 4.19 & 0.0234 & 3.87 & 0.111 & 3.70 & 0.0542 & 3.64 & 0.0682 & 3.76 \\
\hline 0.1 & 0.0234 & 3.62 & 0.0219 & 3.35 & 0.0658 & 3.21 & 0.0373 & 3.16 & 0.0442 & 3.27 \\
\hline 0.2 & 0.0268 & 2.46 & 0.0247 & 2.28 & 0.0309 & 2.20 & 0.0272 & 2.16 & 0.0287 & 2.24 \\
\hline 0.4 & 0.0295 & 1.90 & 0.0273 & 1.74 & 0.0293 & 1.71 & 0.0286 & 1.67 & 0.0298 & 1.73 \\
\hline 0.6 & 0.0295 & 1.74 & 0.0272 & 1.59 & 0.0289 & 1.57 & 0.0284 & 1.53 & 0.0296 & 1.58 \\
\hline 0.8 & 0.0289 & 1.68 & 0.0266 & 1.52 & 0.0279 & 1.51 & 0.0277 & 1.48 & 0.0285 & 1.53 \\
\hline 1.0 & 0.0278 & 1.66 & 0.0257 & 1.49 & 0.0271 & 1.49 & 0.0268 & 1.46 & 0.0277 & 1.51 \\
\hline 2.0 & 0.0234 & 1.68 & 0.0217 & 1.48 & 0.0231 & 1.49 & 0.0225 & 1.47 & 0.0236 & 1.52 \\
\hline 4.0 & 0.0186 & 1.79 & 0.0174 & 1.52 & 0.0194 & 1.56 & 0.0188 & 1.54 & 0.0197 & 1.60 \\
\hline 6.0 & 0.0164 & 1.87 & 0.0153 & 1.55 & 0.0182 & 1.61 & 0.0175 & 1.58 & 0.0185 & 1.65 \\
\hline 8.0 & 0.0152 & 1.93 & 0.0142 & 1.58 & 0.0178 & 1.64 & 0.0170 & 1.62 & 0.0180 & 1.69 \\
\hline 10 & 0.0145 & 1.98 & 0.0137 & 1.60 & 0.0177 & 1.67 & 0.0168 & 1.64 & 0.0179 & 1.72 \\
\hline 20 & 0.0131 & 2.13 & 0.0123 & 1.66 & 0.0180 & 1.75 & 0.0167 & 1.71 & 0.0180 & 1.80 \\
\hline 40 & 0.0124 & 2.25 & 0.0119 & 1.72 & 0.0181 & 1.83 & 0.0168 & 1.77 & 0.0182 & 1.87 \\
\hline 60 & 0.0122 & 2.31 & 0.0116 & 1.75 & 0.0177 & 1.87 & 0.0165 & 1.81 & 0.0178 & 1.90 \\
\hline
\end{tabular}




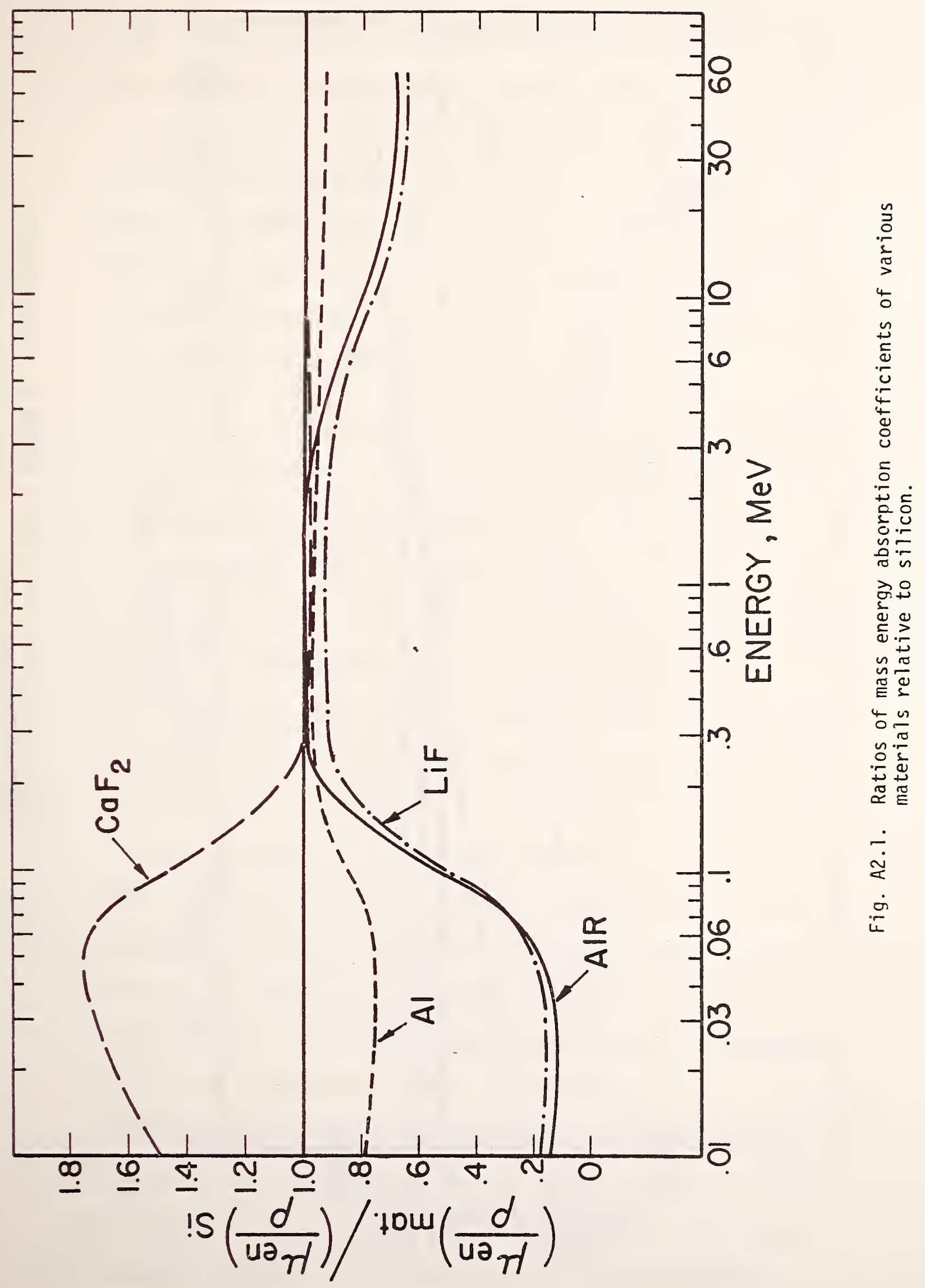




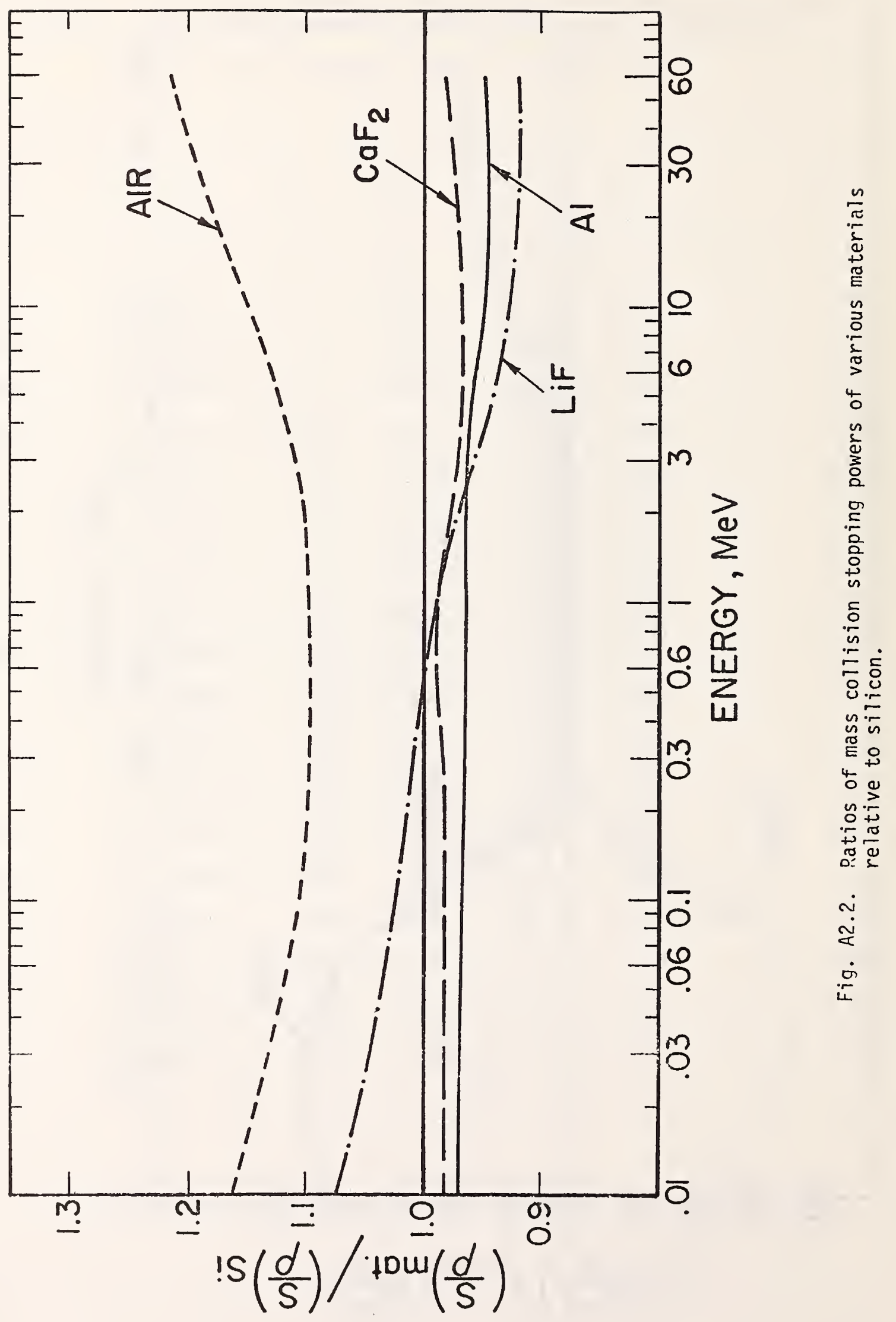




\section{A3. Determination of Electron Equilibrium Thickness}

A3.1 When a material is irradiated by a photon beam, secondary electrons are generated in the material by interaction of the photons with the atoms of the material. At some depth in the material, the number of secondary electrons of a given energy entering a small volume of the material is equal to the number of secondary electrons of the same energy leaving the volume. Within that volume, electron (charged particle) equilibrium is said to exist $[1,16]$.

A3.2 The thickness of material required to approximate electron equilibrium is equal to the range of the maximum-energy secondary electron that can be generated by the primary photons. This thickness as a function of maximum photon energy is shown as curve $A$ in Fig. A3.1 [17]. It has been found that for all practical purposes electron equilibrium is achieved within a few percent of its true condition by a thickness considerably less than the maximum secondary electron range $[18,19]$. This lesser thickness is given by curve B of Fig. A3.1 and approximately corresponds to the depth at which the peak of the depth vs. absorbed dose buildup curve occurs for a given incident photon energy spectrum $[18,20]$. It should be noted that curve $B$ has been determined from data for bremsstrahiung beams with broad energy spectra. The depth of this absorbed-dose peak to some extent depends on the incident photon energy spectrum and the determination of that depth on the method of measurement. Thus, it should be determined experimentally for a particular radiation source.

A3.3 Obviously, it is an advantage to use the least amount of material practical to achieve equilibrium conditions since the intensity of the primary photons is attenuated by this material thickness. 
Correction should be made for this attenuation (as in 9.5) since the dose is being determined for the photon fluence at the point of measurement.

A3.4 A significant error in absorbed-dose determination can occur if the thickness given by curve $B$ is used when an appreciable number of near-maximum-energy secondary electrons are generated by the primary photon beam outside the material of interest. These electrons might come directly from an $x$-ray converter or from direct interaction of the primary photon beam with collimators or other material structures within the vicinity of the measurement area. One method of removing such unwanted electrons from the photon beam would be the use of a transverse magnetic field. However, if this technique is not practical, and it is known or suspected that the primary photon beam contains a significant number of high-energy secondary electrons, then the minimum equilibrium thickness chosen should be equal to the secondary electron range given by curve $A$ of Fig. A3.1.

NOTE A3.1 Fig. A3.1 is based on data calculated or experimentally determined for water. However, equilibrium thickness values obtained from these curves should be within $25 \%$ of the thicknesses required for most materials of low to medium atomic number (up to $\mathrm{Z}=26$ ). 


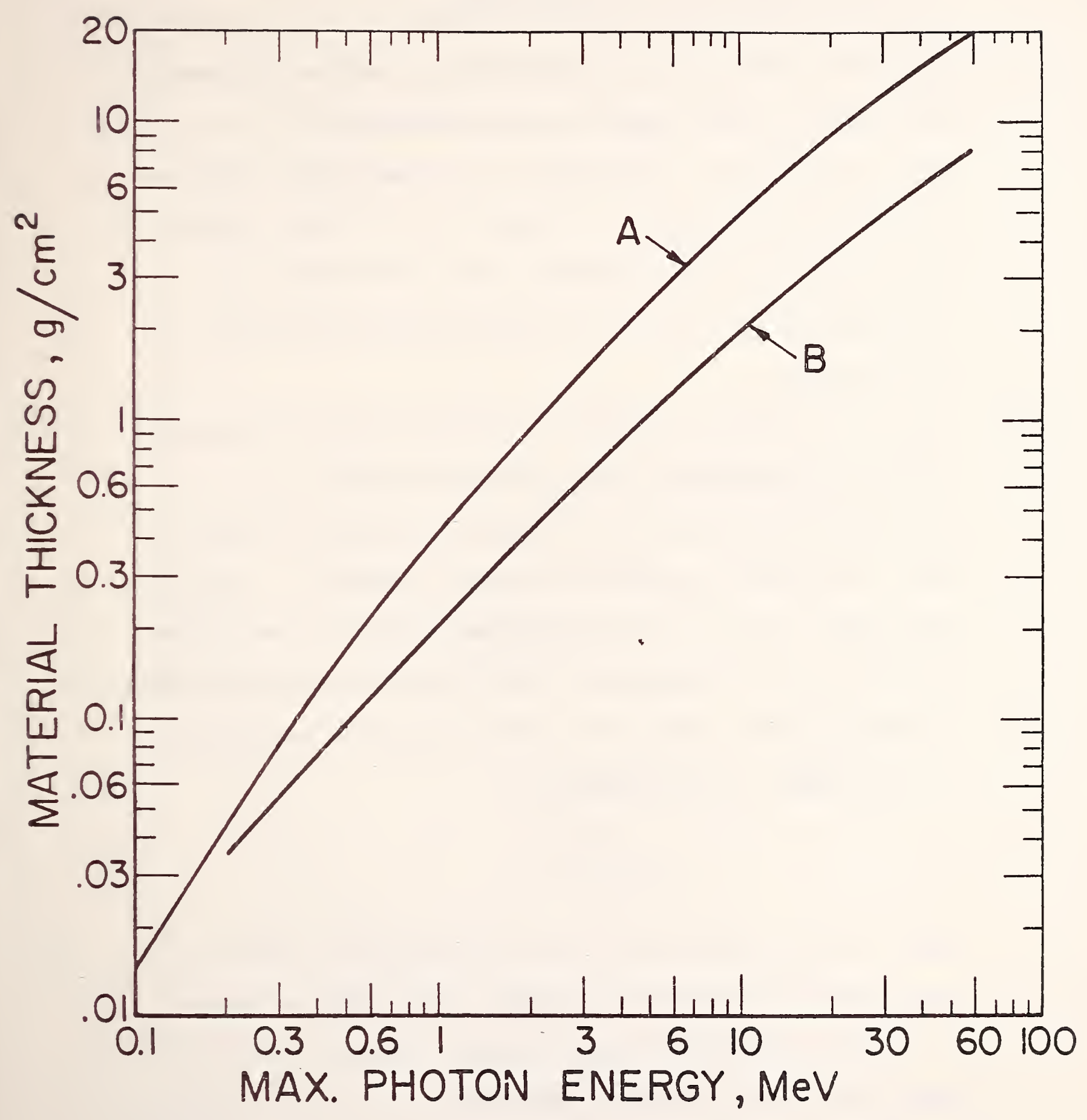

Fig. A3.1 Material thickness required for electron equilibrium. $A$ : electron range. B: depth of peak dose. 
A4. Determination of Test Sample Size

A4.1 The number of TLDs (i.e., the sample size $n$ ) required for each test group in 8.3.3 is based on a two-sided t-test to detect a difference $\delta$ between means of two test groups with a confidence level of $95 \%$ and a probability of failing to detect such a difference of 0.50 (see Sec. 3-3.1.1 of reference 2). The graph of $n$ vs. $d$ in Fig. A4. 1 was derived from table A-8 of reference 2 .

A4.2 The number of TLDs, $n$, required to estimate the mean TLD response at a given absorbed-dose level as described in 9.3.1 is based on the determination of a two-sided confidence interval that is expected to bracket the true mean response, $m, 100(1-\alpha) \%$ of the time. In this case, the confidence level has been chosen as $95 \%$ (i.e., $1-\alpha=0.95$ and $\alpha=0.05$ ) and the confidence interval has been assigned a value of $d= \pm 5 \%$ of the sample mean response, $\bar{Y}_{0}$. The number of TLDs required is

$$
n=\frac{t^{2} s^{2}}{d^{2}},
$$

where $t$ is the percentile of the $t$ distribution at a $95 \%$ confidence level for 29 degrees of freedom. This number of degrees of freedom is determined from the number of samples used for obtaining the estimated standard deviation, $\mathrm{s}$, in 8.1.1 (see sec. 2-3.2 of reference 2).

A4.3 The statistical test methods included here are those generally accepted for product testing. The significance levels chosen are somewhat arbitrary but were selected on the basis of being 
adequate for the performance tests specified. Other more or less stringent acceptable statistical requirements should be assigned upon practical assessment of the overall objectives of the hardness assurance tests. 


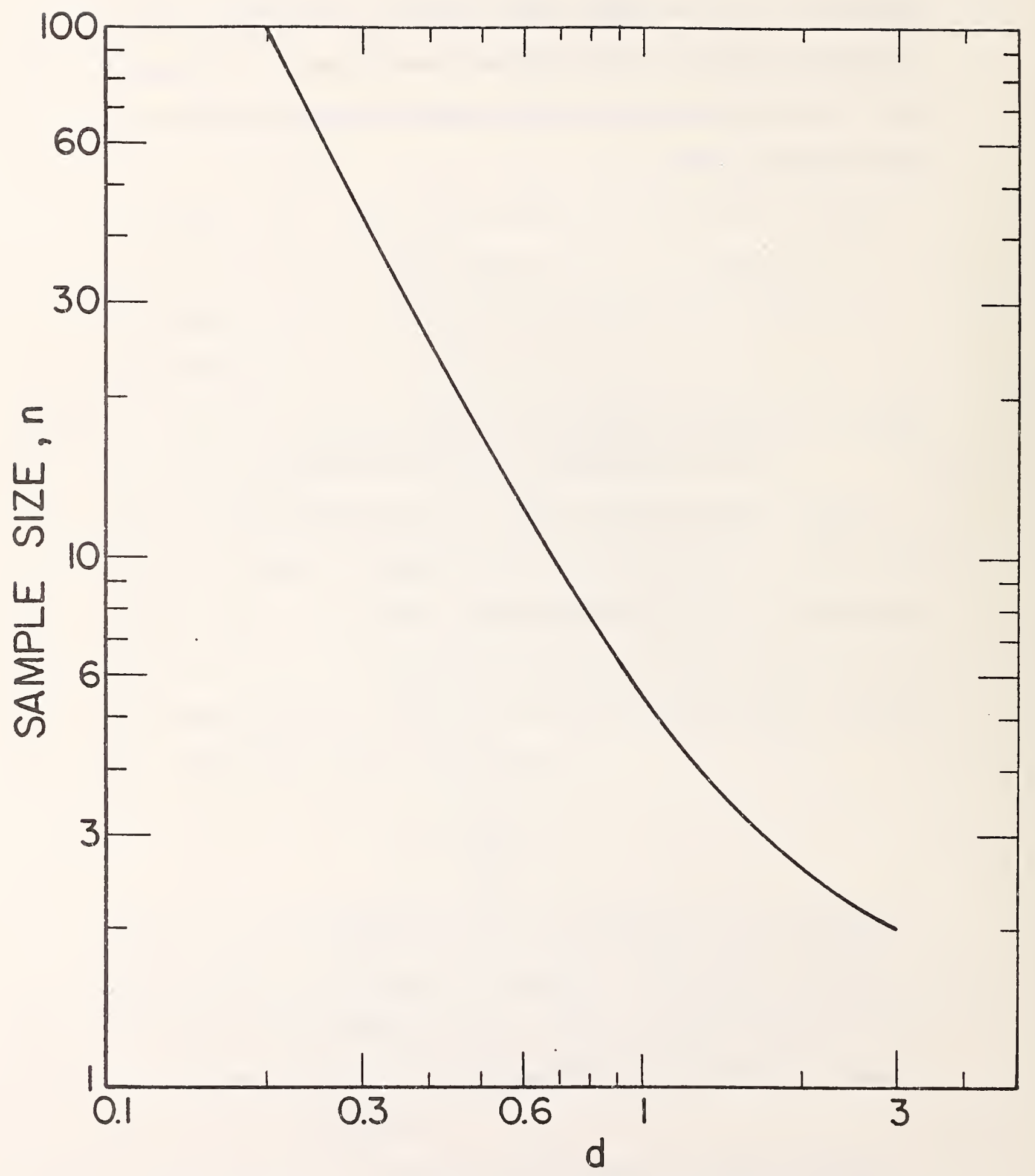

Fig. A4.1 Sample size required to detect difference of two means.

$$
d=\frac{\left|m_{A}-m_{B}\right|}{\sqrt{2 \sigma^{2}}}
$$


1. Aitken, J.J., Huxtable, J., Wintle, A.G., and Bowman, S.G.E. (1974) Age Determination by $T L$ : Review of Progress at 0xford, Proc. of the 4th International Conf. on Luminescence Dosimetry, Krakow, Poland, 1974, Inst. of Nuclear Physics, Krak6w, pp. 1005-1019.

2. Almond, P.R., McCray, K., Espejo, D., and Watanabe, S. (1968) The Energy Response of $\mathrm{LiF}, \mathrm{CaF}_{2}$, and $\mathrm{Li}_{2} \mathrm{~B}_{4} \mathrm{O}$ :Mn from $26 \mathrm{keV}$ to $22 \mathrm{MeV}$, Proc. of the 2nd International Conf. on Luminescence Dosimetry, Gatlinburg, TN, 1968, AEC-CONF-680920, pp. 411-423.

3. Almond, P.R. and McCray, K. (1970), The Energy Response of LiF, CaF , and $\mathrm{Li}_{2} \mathrm{~B}_{4} \mathrm{O}_{7}: \mathrm{Mn}$ to High Energy Radiations, Phys. Med. Biol., 15, pp. $335-342$.

4. Attix, F.H. (1962), Dosimetry by Solid State Devices, USNRL Report 5777 , U.S. Naval Research Laboratory, Washington, D.C.

5. Attix, F.H. (1964), Present Status of Dosimetry by Radiophotoluminescence and Thermoluminescence Methods, USNRL Report 6145, U.S. Naval Research Laboratory, Washington, D.C.

6. Becker, K., Hong-Wei Lu, R. and Weng, P. (1971), Environmental and Personnel Dosimetry in Tropical Countries, Proc. of the 3rd International Conf. on Luminescence Dosimetry, Ris $\varnothing$, Denmark, 1971, Ris $\phi$ Report No. 249, pp. 960-984.

7. Becker, K. (1973) Solid State Dosimetry, CRC Press, Cleveland, Ohio.

8. Booth, L.R., Johnson, T.L., and Attix, F.H. (1971), Use of Miniature Glass-Needle-Type TL Dosimeters in Finger-Ring Applications, USNRL Report 7276, U.S. Naval Research Laboratory, Washington, D.C.

9. Burgkhardt, B., Singh, D., and Piesch, E. (1977) High-Dose Characteristics of $\mathrm{CaF}_{2}$ and $\mathrm{Ca} \mathrm{SO}_{4}$ Thermoluminescent Dosimeters, Nucl. Instr. and Methods, 141, Pp. 363-368.

10. Burgkhardt, B., Piesch, E., and Singh, D. (1978), High-Dose Characteristics of $\mathrm{LiF}$ and $\mathrm{Li}_{2} \mathrm{~B}_{4} \mathrm{O}_{7}$ Thermoluminescent Dosimeters, Nucl. Instr, and Methods, 148, pp. 613-617.

11. Burke, G. de P. (1974), Thermoluminescence of $\mathrm{CaF}_{2}: \mathrm{Mn}$ Exposed at Elevated Temperatures to a Constant Rate of Low-Level Radiation. Proc. of the 4th International Conf. on Luminescence Dosimetry, Krakow, Poland, 1974, Inst. of Nuclear Physics, Krak6w, pp. 315-345.

12. Burke, G. de P. (1977), Compilation of Available Studies of TLD Stability, Proceedings of 5th International Conf. on Luminescence Dosimetry, San Paulo, Brazil, 1977, I. Physikalisches Inst., Giessen, W. Germany, pp. 84-93.

13. Cameron, J.R., Suntharalingam, N., and Kenny, G.N. (1968), Thermoluminescent Dosimetry, The University of Wisconsin Press, Madison, WI. 
14. Chan, F.K. and Burlin, T.E. (1970), The Energy-Size Dependence of the Response of Thermoluminescent Dosimeters to Photon Irradiation, Health Physics, 18, pp. 325-332.

15. Commission of the European Communities (1975), Radiological Protection 3, Technical Recommendations for the Use of Thermoluminescence for Dosimetry in Individual Monitoring for Photons and Electrons from External Sources, EUR 5358 e.

16. Cluchet, J. and Joffre, H. (1967) Applications of Thermoluminescence Dosimetry in Health Physics, Proc. of the 1st International Conf. on Luminescence Dosimetry, Stanford, CA. 1965, AEC-CONF-650637, pp. 249-258.

17. Dua, S.K., Boulenger, R., Ghoos, L., and Mertens, E. (1971) Mixed Neutron-Gamma Dosimetry, Proc. of the 3rd International Conf. on Luminescence Dosimetry, Ris $\phi$, Denmark, 1971, Ris $\varnothing$ Report No. 249, pp. 1074-1088.

18. Ehrlich, M. and Placious, R.C. (1968), Thermoluminescence Response of $\mathrm{CaF}_{2}: \mathrm{lin}$ in Polytetrafluoroethylene to Electrons, Health Physics, 15 , pp. 341-350.

19. Ehrlich, M. (1970), Response of Thermoluminescent Dosimeters to $15 \mathrm{MeV}$ Electrons and ${ }^{60}$ Co Gamma Rays, Health Physics, 18, pp. 287-289.

20. Ehrlich, M. (1971), Influence of Size of $\mathrm{CaF}_{2}: \mathrm{Mn}$ Thermoluminescence Dosimeters on ${ }^{60}$ Co Gamma-Ray Dosimetry in Extended Media, Proc. of the 3rd International Conf. on Luminescence Dosimetry, Ris $\phi$, Denmark, 1971, Ris $\phi$ Report No. 249, pp. 550-560.

21. Endres, G.W.R. and Kocher, L.F. (1968), The Response of Selected Thermoluminescent Material to Fast-Neutron Exposures, Proc. of the 2nd International Conf. on Luminescence Dosimetry, Gatlinburg, TN, 1968, AEC-CONF 680920, pp. $486-500$.

22. Fitzsimmons, C.K. and Horn, H.H. (1972), Environmental Monitoring with Thermoluminescent Dosimeters - An Evaluation of the System and a Comparison to Photographic Methods, SWRHL-58, Southwestern Radiological Health Laboratory, U.S. Department of Health, Education and Welfare.

23. Fowler, J.F. and Attix, F.H. (1966), Radiation Dosimetry, Vol. II, 2nd Edition, F.H. Attix, W.C. Roesch, and E. Tochilin, Eds., Academic Press, New York, pp. 269-290.

24. Gayton, F.M., Harvey, J.R. and Jackson, J. H. (1972), Thermoluminescence and Its Applications in Reactor Environments, J. British Nucl. Energy Society, 11, pp. 125-140.

25. Ginther, R.J. and Kirk, R.D. (1956), Thermoluminescence of $\mathrm{CaF}_{2}$ : Rin and Its Application to Dosimetry, Report of NRL Progress, Sept 12-20, U.S. Naval Research Laboratory, Washington, D.C.

26. Ginther, R.J. and Kirk, R.D. (1957), The Thermoluminescence of $\mathrm{CaF}_{2}: \mathrm{Mn}$, J. of the Electrochemical Society, 104, pp. 365-369. 
27. Corbics, S.G. and Attix, F.H. (1964), Brief Evaluation of the U.S. Navy Prototype Thermoluminescent Dosimetry System: Computer Indicator, RADIAC, CP-748(XN-1)/PD and Detector, RADIAC, DT-284(XN-1)6PD, NRL Test and Evaluation Report 37, U.S. Naval Research Laboratory, Washington, D.C.

28. Gorbics, S.G. (1967), Emission Spectra of Various Thermoluminescent Materials, Proc. of the 1st International Conf. on Luminescence Dosimetry, Stanford, CA., 1965, AEC-CONF-650637, pp. 167-182.

29. Gorbics, S.G., Attix, F.H. and Pfaff, J.H. (1967), Temperature Stability of $\mathrm{CaF}_{2}: \mathrm{Mn}$ and LiF (TLD-100) Thermoluminescent Dosimeters, Int. J. Appl. Rad. and Isotope, 18, pp. 625-630.

30. Gorbics, S.G. and Attix, F.H. (1968), LiF and $\mathrm{CaF}_{2}:$ Mn Thermoluminescent Dosimeters in Tandem, Int. J. App1. Rad. and Isotope, 19, pp. 31-89.

31. Gorbics, S.G., Nash, A.E., and Attix, F.H. (1968), Thermal Quenching of Luminescence in Six Thermoluminescent Dosimetry Phosphors, Proc. of the 2nd International Conf. On Luminescence Dosimetry, Gatlinsburg, TN, 1968, AEC-CONF-680920, pp. 587-606.

32. Gorbics, S.G., Nash, A.E. and Attix, F.H. (1969), Thermal Quenching of Luminescence in Six Thermoluminescent Phosphors - I, Int. J. Appl. Rad. and Isotope, 20, pp. 829-841.

33. Gorbics, S.G., Attix, F.H., and Kerris, K. (1973), Thermoluminescent Dosimeters for High-Dose Applications, Health Physics, 25, pp. 499-506.

34. Gross, K.C., McNamara, E.J., and Brinck, W.L. (1976), Factors Affecting the Use of $\mathrm{CaF}_{2}: \mathrm{Mn}$ Thermoluminescent Dosimeters for Low-Level Environmentai Radiation Monitoring, USEPA Report 600/4-76-035.

35. Johnson, T.L. and Attix, F.H. (1967), Pilot Comparison of Two Thermoluminescent Dosimetry Systems with Film Badges in Routine Personnel Monitoring, NRL Technical and Evaluation Report 69, U.S. Naval Research Laboratory, Washington, D.C.

36. Kiefer, H., Maushart, R., and Mejdah1, V. (1969), Radiation Dosimetry, Vol. III, 2nd Edition, F.H. Attix, W.C. Roesch ard E. Tochilin, Eds. Academic Press, New York, pp. 584-585.

37. Lin, F.M. and Cameron, J.R. (1968), A Bibliography of Thermoluminescent Dosimetry, Health Physics, 14, pp. 495-514.

38. Lucas, A.C. and Kapsar, B.M. (1974), Operational Importance of Retrapping in $\mathrm{CaF}_{2}: \mathrm{Mn}$ Dosimeters, Health Physics, 27, 600-603.

39. Marrone, M.J. and Attix, F.H. (1964), Damage Effects in $\mathrm{CaF}_{2}: \mathrm{Mn}$ and LiF Thermoluminescent Dosimeters, Health Physics, 10, pp. 431-436.

40. Nakajima, T., Hiraoka, T., and Habu, T. (1968), Energy Dependence of LiF and $\mathrm{CaF}_{2}$ Thermoluminescent Dosimeters for High Energy Electrons, Health Physics, 14, pp. 266-267. 
41. Nash, A.E., Attix, F.H., and Schulman, J.H. (1967), Spurious Thermoluminescence of $\mathrm{CaF}_{2}: \mathrm{Mn}$ and LiF (TLD-100), Proc. of the 1st International Conf. on Luminescence Dosimetry, Stanford, CA. 1965, AEC-CONF650637 , pp. 244-258.

42. Palmer, R.C., Rutland, D., Lagerquist, R., and Blase, E.F. (1966), A Prototype Thermoluminescent Dosimetry System for Personnel Monitoring, Int. J. A.ppl. Rad. and Isotope, 17, pp. 399-411.

43. Partridge, J.E., Windham, S.T., Lobde11, J.L., and Oppold, J.A. (1973), Suitability of Glass-Encapsulated $\mathrm{CaF}_{2}:$ Mn Thermoluminescent Dosimeters for Environmental Radiation Surveillance, USEPA Report ORP/EERF 73-1.

44. Pendurkar, H.K., Boulenger, R., Ghoos, L., Nicasi, W., and Mertens, E. (1971), Energy Response of Certain Thermoluminescent Dosimeters and Their Application to the Dose Measurements, Proc. of 3rd International Conf. on Luminescence Dosimetry, Ris $\varnothing$, Denmark, 1971, Ris $\emptyset$ Report No. 249. pp. 1089-1106.

45. Prokic, M. (1971), Determination of the Sensitivity of the CaF $2: M n$ Thermoluminescent Dosimeter to Neutrons, Proc. of the 3rd International Conf. on Luminescence Dosimetry, Ris $\phi, 1971$, Ris $\varnothing$ Report No. 249, pp. $1051-1062$.

46. Schulman, J.H., Attix, F.H., West, E.J., and Ginther, R.J. (1960a), New Thermoluminescent Dosimeter, The Review of Scientific Instruments, 31 , pp. 1263-1269.

47. Schulman, J.H., Ginther, R.J., Kirk, R.D., and Goulart, H.S. (1960b), Thermoluminescent Dosimeter Has Storage Stability Linearity, Nucleonics, 18, pp. 92-102.

48. Schulman, J.H. (1967a), Survey of Luminescence Dosimetry, Proc. of the 1st International Conf. on Luminescence Dosimetry, Stanford, CA., 1965, AEC-CONF-650637, pp. 3-33.

49. Schulman, J.H. (1967b), Principles of Solid State Luminescence Dosimetry, Solid State and Chemical Radiation Dosimetry in Medicine and Biology, IAEA, Vienna, pp. 3-30.

50. Schulman, J.H., Ginther, R.J., Gorbics, S.G., Nash, A.E., West, E.J., and Attix, F.H. (1969), Anomalous Fading of $\mathrm{CaF}_{2}: \mathrm{Mn}$ Thermoluminescent Dosimeters, Int. J. of Appl. Rad. and Isotopes, 20, pp. 523-529.

51. Spurny,, Z. (1969), Additional Bibliography of Thermoluminescent Dosimetry, Health Physics, 17, pp. 349-354.

52. Spurny, Z. (1971), Simultaneous Estimation of Exposure and Time Elapsed Since Exposure Using Multipeaked Thermoluminescent Phosphors, Health Physics, 21, pp. 755-761.

53. Spurný, Z. and Kvasnicka, J. (1974), Short-Term Fading of Different Thermoluminescent Phosphors, Proc. of the 4th International Conf. on Luminescence Dosimetry, Kraków, Poland, 1974, Institute of Nuclear Physics, Krakow, pp. 255-261. 
54. Spurný, Z, and Sulcova, J. (1973), Bibliography of Thermoluminescent Dosimetry (1968-1972), Health Physics, 24, pp. 573-587.

55. Tochilin, E. and Goldstein, N. (1966), Dose Rate and Spectral Measurements from Puised X-Ray Generators, Health Physics, 12, pp. 1705-1713.

56. Tochilin, E., Goldstein, N., and Miller, W.G. (1969), Beryllium Cxide as a Thermoluminescent Dosimeter, Health Physics, 16, pp. 1-7.

57. Uran, D., Knezevic, M., Suznik, D., and Kolar, D. (1971), Some Dosimetric properties of Sintered Activated $\mathrm{CaF}_{2}$ Dosimeters, Proc. of the 3rd International Conf. on Luminescence Dosimetry, Ris $\phi$, Denmark, 1971, Risø Report No. 249.

58. Wintle, A.G., Aitken, M.J., and Huxtable, J. (1971), A.bnormal Thermoluminescence Fading Characteristics, Proc. of the 3rd International Conf. on Luminescence Dosimetry, Krakow, 1974, Inst. of Nuclear Physics, krakow, Poland. 
Department of Defense

Assistant to the Secretary of Defense Atomic Energy

Washington, DC 20301

ATTN Executive Assistant

Director

Command \& Control Technical Center

Department of Defense

The Pentagon, Rm BE 685

Washington, DC 20301

ATTN C-362 Mr. Adkins

Defense Documentation Center

Cameron Station

Alexandria, VA 22314

ATTN TC

Commander

Defense Electronic Supply Center

1507 Wilmington Pike

Dayton, $\mathrm{OH} 45444$

ATTN DESC-EQE J. Counsil

ATTN DESC-ECS J. Dennis

ATTN DESC-ECS D. Droege

ATTN DESC-EQE R. Grillmeier

ATTN DESC-ECS D. Hill

ATTN DESC-ECT J. Niles

ATTN DESC-ECP B. Nunke

\section{Director}

Defense Logistics Agency

Cameron Station

Alexandria, VA 22314

ATTN DLA-SE

ATTN DLA-QEL J. Slattery

Defense Material Specifications and

Standards Office

Room 105 Dwyer Bldg.

3320 Duke Street

Alexandria, VA 22314

ATTN L. Fox

\section{Director}

Defense Nuclear Agency

Washington, DC 20305
ATTN DDST
ATTN TITL
ATTN TISI Archives
ATTN RAEV H. Fitz, Jr.
ATTN RAEV Maj. M. Kemp

Commander

Field Command

Defense Nuclear Agency

Kirtland AFB, NM 87115

ATTN FCPR

Chief

Livermore Division Fld Command DNA

Department of Defense

Lawrence Livermore Laboratory

P.O. Box 808

Livermore, CA 94550

ATTN FCPRL

Under Secy of Def for Rsch \& Engrg

Department of Defense

Washington, DC 20301

ATTN AE

ATTN SSS

Director

National Security Agency

Ft. Meade, MD 20755

ATTN T. Brown

ATTN G. Daily

ATTN P. Deboy

Director

Defense Supply Agency

DSAH/SE 4 A586

Cameron Station

Alexandria, VA 22314

Department of the Army

Commander

Aberdeen Proving Ground

Department of the Army

Aberdeen Proving Ground, MD 21005

ATTN S. Harrison

Director

BMD Advanced Technology Center

Huntsville Office

Department of the Army

P.O. Box 1500

Huntsville, AL 35807

ATTN ATC-T

ATTN BMDSC-TEN R. DeKalb

Deputy Chief of Staff for

Rsch Dev and Acq

Department of the Army

Washington, DC 20310

ATTN LTC G. Ogden 
Commander

Harry Diamond Laboratories

Department of the Army

2800 Powder Mill Road

Adelphi, MD 20783
ATTN DEHLD-N-P
F. Balicki
ATTN DEHLD-N-RBH
H. Eisen
ATTN DEHLD-N-RBH
J. Halpin
ATTN DELHD-N-RBH

Commander

Redstone Scientific Information CTR

U.S. Army R \& D Command

Redstone Arsenal, AL 35809

ATTN Chief, Documents

\section{Commander}

U.S. Army Armament Research \&

Development Command

Dover, NJ 07801

ATTN DRDAR-LCA-PD

Project Officer

U.S. Army Electronics Rsch \& Dev Command

Fort Monmouth, NJ 07703

ATTN D. Huewe

Commander

U.S. Army Nuclear \& Chemical Agency

7500 Backlick Road

Building 2073

Springfield, VA 22150

ATTN MONA-WE Maj A. Lind

ATTN Nuc Surv Cmte Col A. Lowrey

Commander

White Sands Missile Range

Department of the Army

White Sands Missile Range, NM 88002

ATTN STEWS-TE-AN T. Leura

ATTN STEWS-TE-AN Maj. L. Meason

ATTN STEWS-TE-NT M. Squires

ATTN

R. Williams

Department of the Navy

Chief of Naval Operations

Department of the Navy

Washington, DC 20350

ATTN OP985F

Chief of Naval Research

Ballston Center Tower 非 1

800 N. Quincy Street

Arlington, VA 22217

ATTN Code 220 D. Lewis

ATTN Code 427 L. Cooper
Commander

Naval Air Systems Command

Washington, DC 21360

ATTN Air 350F

Commander

Naval Electronic Systems Comd

Department of the Navy

Washington, DC 20360

ATTN 5045.11 C. Suman

Commander

Naval Ocean Systems Center

San Diego, CA 92152

ATTN Code 4471 (Tech Lib)

Superintendent (Code 1424)

Naval Postgraduate School

Monterey, CA 93940

ATTN Code 2124 Tech Rpts Librarian

Commanding Officer

Naval Research Laboratory

Washington, DC 20375

ATTN Code 6701 J. Brown

ATTN Code 5210 J. Davey

ATTN Code 6627 C. Guenzer

ATTN Code $5216 \mathrm{H}$. Hughes

ATTN Code 6600 J. McElhinney

ATTN Code 6650 A. Namenson

ATTN Code 6601 E. Wolicki

Commander

Naval Sea Systems Command

Washington, DC 20362

ATTN SEA-9931 R. Lane

Commander

Naval Ship Engineering Center

Washington, DC 20362

ATTN Code 6174D2

Commander

Naval Surface Weapons Center

White Oak, Silver Spring, MD 20910
ATTN
J. Downs
ATTN
$R$. Jenkins
ATTN Code WA52
R. Smith

Commander

Naval Weapons Center

China Lake, CA 93555

ATTN Code 533 (Tech Lib)

Commanding Officer

Naval Weapons Evaluation Facility

Kirtland Air Force Base

Albuquerque, NM 87117

ATTN Code AT-6 
Commanding Officer

Naval Weapons Support Center

Crane, IN 47522

ATTN Code 7024 T. Ellis

ATTN Code 7024 J. Munarin

ATTN Code 7024 J. Ramsey

\section{Director}

Strategic Systems Project Office

Department of the Navy

Washington, DC 20376

ATTN Code 2015

ATTN Code 230

D. Gold

ATTN Code 2701

J. Pitsenberger

ATTN Code 2730

P. Spector

\section{Department of the Air Force}

\section{Commander}

Air Force Aero-Propulsion Laboratory, AFSC

Wright Patterson AFB, OH 45433

ATTN POD P. Stover

\section{Commander}

Air Force Avionics Laboratory, AFSC

Wright-Patterson AFB, OH 45433

ATTN TEA R. Conklin

ATTN DHE $H$. Hennecke

Commander

Air Force Institute of Technology

Wright-Patterson AFB, OH 45433

ATTN ENP C. Bridgman

\section{Commander}

Air Force Materials Laboratory, AFSC

Wright-Patterson AFBV, OH 45433

ATTN LTE

Headquarters

Air Force Systems Command

Andrews AFB

Washington, DC 20334

ATTN DLCA

$\begin{array}{ll}\text { ATTN } & \text { Capt. T. Seale } \\ \text { ATTN XRLA } & \text { Maj. R. Stead }\end{array}$

Air Force Technical Applications Center

Patrick AFB, FL 32925

ATTN TAE
Commander

Air Force Weapons Laboratory, AFSC Kirtland AFB, NM 87117

ATTN SUL

ATTN ELP J. Ferry

ATTN ELP Capt. M. Knoll

ATTN ELP Lt. Col. A. Loggins

ATTN ELP R. Maier

ATTN ELP J. Mullis

Headquarters

Electronic Systems Division

Air Force Systems Command

Hanscom AFB, MA 01731

ATTN Technical Library

Commander

Foreign Technology Division

Air Force Systems Command

Wright-Patterson AFB, OH 45433

ATTN FTD/PDJV

ATTN ETDP B. Ballard

Air Force Technical Applications Center Patrick AFB, FL 32925

ATTN TAE

Commander

Ogden ALC

Department of the Air Force

Hill AFB, UT 84406

ATTN MMETH Maj. R. Blackburn

ATTN MMGRW G. Fry

ATTN MMEDD C. Graham

ATTN MMIFM S. Mallory

ATTN MMETH Capt. R. Padfield

ATTN MMIFM D. Stanger

ATTN MMETH Maj. F. Walter

Commander

Rome Air Development Center

RADC/RBRM

Griffiss AFB, NY 13441

ATTN RBRM J. Brauer

ATTN RBRP C. Lane

Commander

Rome Air Development Center

Hanscom AFB, MA 01731

ATTN ESR R. Buchanan

ATTN ETS R. Dolan

ATTN ESE A. Kahan

ATTN ESR W. Shedd

ATTN ESR P. Vail 
Commander

Space \& Missile Systems Command/SK

Post Office Box 92960

Worldway Postal Center

Los Angeles, CA 90009

ATTN AQM

ATTN AQT

Lt. Col. K. Blakney

ATTN DYS

Maj. L. Darda

ATTN SZJ

Maj. R. Davis

ATTN

C. Kelly

ATTN MNNL

Lt. Col. S. Kennedy

ATTN SKF

P. Stadler

Commander

Space and Missile Systems Organization Norton AFB, CA 92409

ATTN MNNG

ATTN MNNH Capt. J. Tucker

National Aeronautics and Space Agency

NASA Headquarters

Washington, D.C. 20546

ATTN J. Murphy

\section{Director}

NASA Ames Research Center

M/S 2445

Moffett Field, CA 90035

ATTN G. DeYoung

\section{Director}

NASA Goddard Space Flight Center Greenbelt, MD 20771
ATTN Code 311
J. Adolphsen
ATTN Code 755.1 V. Danchenko

NASA-Lewis Research Center

210100 Brook Park Rd

Cleveland, Ohio 44135

ATTN M. Baddour

\section{Director}

NASA Marshall Space Flight Center

Huntsville, AL 35812

ATTN EGO2

ATTN EC43

L. Hamiter

ATTN

M. Nowakowski

ATTN
Department of Energy

Albuquerque Operations Office

P.O. Box 5400

Albuquerque, NM 87115

ATTN Document Control for WSSB

University of California

Lawrence Livermore Laboratory

P.O. Box 808

Livermore, CA 94550

ATTN Doc Con for Technical Information Dept.

Los Alamos Scientific Laboratory

P.O. Box 1663

Los Alamos, NM 87545

ATTN Doc Con for J. Freed

Office of Military Application

Department of Energy

Washington, DC 20545

ATTN Doc Con for Classified Library

Sandia Laboratories

P.O. Box 5800

Albuquerque, NM 87185

ATTN J. Barnum

ATTN F. Coppage

ATTN W. Dawes

ATTN R. Gregory

ATTN J. Hood

Solar Energy Research Institute Golden, Colorado 80413

ATTN A. Stanley

\section{Department of Commerce}

Director

National Bureau of Standards

Washington, D.C. 20234

ATTN A353 Phy S. Chappell

ATTN A361 Tech J. French

ATTN A327 Tech K. Galloway

ATTN C216 RadP J. Humphreys

ATTN A327 Tech J. Mayo-Wells

ATTN A353 Tech W. Bullis

ATTN A327 Tech R. Scace 


\section{Other Government}

Central Intelligence Agency

Hq Bldg, Rm. 5 G48

Washington, DC 20505

ATTN RD/SI

\section{Department of Defense Contractors}

Advanced Microdevices, Inc.

901 Thompson Place

Sunnyvale, CA 94086

ATTN J. Schlageter

Aerojet Electro-Systems Co.

Division of Aerojet-General Corp.

P.O. Box 296

1100 W. Hollyvale Drive

Azusa, CA 91702

ATTN T. Hanscome

Aeronutronic-Ford Corporation

Division 3939 Fabian Way

Palo Alto, CA 94303

ATTN D. Cadle

Aeronutronic Ford Corporation

Electronic Technology Department

Ford Road

Newport Beach, CA 92663

ATTN J. Davison

Aerospace Corporation

P.O. Box 92957

Los Angeles, CA 90009

ATTN S. Bower

ATTN D. Fresh

ATTN W. Willis

\section{ARACOR}

1223 E. Arques Avenue

Sunnyvale, CA 94086

ATTN R. Armistead

Battelle Memorial Institute

$505 \mathrm{King}$ avenue

Columbus, $\mathrm{OH} 43201$

ATTN R. Thatcher

\section{BDM Corporation}

2600 Yale Boulevard, S.E.

Albuquerque, NM 87106

ATTN D. Alexander

ATTN R. Pease

ATTN D. Wunch
Bendix Corporation

Flight Systems Division

Dept. 7831

Teterboro, NJ 07608

ATTN E. Meeder

Boeing Aerospace Company

MS-2R-00

P.O. Box 3999

Seattle, WA 98124

ATTN I. Arimura

ATTN D. Egelkrout

ATTN A. Johnston

ATTN C. Rosenberg

ATTN W. Rumpza

Burr-Brown Research Corporation International Airport Ind. Park P.O. Box 11400

Tucson, AZ 85734

ATTN H.C. Smith

California Institute of Technology Jet Propulsion Laboratory 4800 Oak Grove Drive Pasadena, CA 91103

ATTN W. Price

ATTN A. Shumka

ATTN A. Stanley

Charles Stark Draper Laboratories 555 Technology Square Mail Station 62

Cambridge, MA 02139

ATTN R. Bedingfield

ATTN P. Greiff

ATTN C. Lai

ATTN R. Ledger

ATTN A. Schutz

Cincinnati Electronics Corp.

2630 Glendale-Milford Road

Cincinnati, $\mathrm{OH} 45241$

ATTN L. Hammond

ATTN C. Stump

Control Data Corporation

P.O. Box 0

Minneapolis, MN 55440

ATTN J. Meehan

Denver Research Institute

University of Colorado

P.0. Box 10127

Denver, CO 80210

ATTN F. Venditti 
E-Systems, Inc,,

P.O. Box 6118

Dallas, TX 75222

ATTN K. Reis

EMM Corporation

3883 No. 28th Avenue

Phoenix, AZ 85017

ATTN F. Krch

Exp. \& Math. Physics Consultants

P.O. Box 66331

Los Angeles, CA 90066

ATTN T. Jordan

Fairchild Camera and Instrument Corp. 464 Ellis Street

Mountain View, CA 94040

ATTN D. Myers

ATTN R. Marshall

Ford Aerospace \& Communications Corp.

Ford \& Jamboree Roads

Newport Beach, CA 92663

ATTN Tech Info Services

Franklin Institute

20th Street and Parkway

Philadelphia, PA 19103

ATTN R. Thompson

Garrett Corporation

P.O. Box 92248

9851 Sepulveda BIvd

Los Angeles, CA 90009

ATTN R. Weir

General Dynamics Corporation

Convair Aerospace Division

P.O. Box 1128

San Diego, CA 92112

ATTN W. Hansen

General Dynamics Corporation

Aerosystems Division

P.O. Box 748

Ft. Worth, TX 76101

ATTN O. Wood

ATTN R. Fields

General Electric Company

P.O. Box 5000

Binghamton, NY 13902

ATTN D. Pepin
General Electric Company

Aerospace Elec Sys Dept

French Road Plant

Utica, NY 13503

ATTN D. Cole

ATTN W. Patterson

ATTN J. Gibson

General Electric Company

Aircraft Engine Business Group

Evendale Plant, Int Hwy 755

Cincinnati, OH 45215

ATTN R. Hellen

General Electric Company

Ordnance Systems

100 Plastics Avenue

Pittsfield, MA 01201

ATTN J. Reidl

General Electric Company

Re-entry \& Environmental Systems Div.

P.O. Box 7722

3198 Chestnut Street

Philadelphia, PA 19101

ATTN R. Benedict

ATTN W. Palchefsky, Jr.

ATTN W. Patterson

ATTN Tech. Lib.

General Electric Company

Valley Forge Space Center

P.O. Box 8555

Philadelphia, PA 19101

ATTN R. Casey

ATTN D. Long

ATTN J. Peden

ATTN L. Sivo

General Electric Company--Tempo 2560 Huntington Avenue

Suite 300

Alexandria, VA 22303

ATTN W. Alfonte

General Electric Company--Tempo

Center for Advanced Studies

816 State Street (P.O. Drawer QQ)

Santa Barbara, CA 93102

ATTn DASIAC E. Espig

General Research Corporation

Santa Barbara Division

P.O. Box 6770

Santa Barbara, CA 93111

ATTN R. Hill

ATTN Tech. Inf. Off. 
Georgia Institute of Technology

Georgia Tech Research Institute

Atlanta, GA 30332

ATTN R. Curry

Goodyear Aerospace Corporation

Arizona Division

Litchfield Park, AZ 85340

ATTN Security Control Station

Grumman Aerospace Corporation

South Oyster Bay Road

Bethpage, NY 11714

ATTN J. Rogers

GTE Sylvania, Inc.

Electronics Systems GRP-Eastern Div

77 A Street

Needham, MA 02194

ATTN C. Thornhill

ATTN L. Pauplis

GTE Sylvania Inc.

189 B Street

Needham Heights, MA 02194

ATTN P. Fredrickson

ATTN H\& V Group

ATTN C. Ramsbottom

ATTN J. Waldron

ATTN $H_{\text {. Ullman }}$

Harris Corporation

Harris Semiconductor Division

P.O. Box 883

Melbourne, FLA 32901

ATTN J. Cornell

ATTN C. Anderson

Honeywell Inc.

Aerospace \& Defense Group

13350 U.S. Highway 19 North

St. Petersburg, FL 33733

ATTN C. Cerulli

Honeywell, Inc.

Government \& Aeronautical Prod. Div. 600 2nd Street, North

Hopkins, MN 55343

ATTN K. Gaspard

Honeywell, Inc.

Government \& Aeronautical Pro.

2600 Ridgway Road

Minneapolis, MN 55440

ATTN R. Gumm
Honeywell, Inc.

Radiation Center

2 Forbes Road

Lexington, MA 02173

ATTN Technical Library

Hughes Aircraft Company

Centinela and Teale

Culver City, CA 90230

ATTN R. McGowan

ATTN J. Singletary

Hughes Aircraft Company

El Segundo Site

P.O. Box 92919

Los Angeles, CA 90009

ATTN E. Smith

ATTN W. Scott

IBM

Department L99, Bldg. 002A

Route 17C

Owego, NY 13827

ATTN F. Tietse

ATTN H. Mathers

ATTN T. Martin

IBM Research Laboratories

Box 218

Yorktown Heights, NY 10598

ATTN J. Ziegler

IIT Research Institute

10 West 35th Street

Chicago, IL 60616

ATTN I. Mindel

Institute for Defense Analyses

400 Army-Navy Drive

Arlington, VA 22202

ATTN Tech. Info. Services

Intel Corporation

3065 Bowers Avenue

Mail Stop 1-156

Santa Clara, CA 95051

ATTN M. Jordan

International Tel. \& Telegraph Corp. 500 Washington Avenue

Nutley, NJ 07110

ATTN A. Richardson

ATTN Dept 608

Intersil Inc.

3250 Scott Boulevard

Santa Clara, CA 95051

ATTN D. MacDonald 
IRT Corporation

P.O. Box 81087

San Diego, CA 92138

ATTN J. Harrity

JAYCOR

1401 Camino del Mar

Del Mar, CA 92014

ATTN L. Scott

Johns Hopkins University

Applied Physics Laboratory

Johns Hopkins Road

Laurel, MD 20810

ATTN P. Partridge

Kaman Sciences Corporation

P.O. Box 7463

Colorado Springs, CO 80933

ATTN J. Lubell

Litton Systems, Inc.

Guidance and Control Systems Division 5500 Canoga Avenue

Woodland Hills, CA 91364

ATTN G. Maddox

Lockheed Missiles and Space Co., Inc.

P.O. Box 504

Sunnyvale, CA 94088

ATTN P. Bene

ATTN H. Phillips

ATTN E. Smith

ATTN C. Thompson

Lockheed Missiles and Space Co., Inc.

Research Division

3251 Hanover Street

Palo Alto, CA 94304

ATTN J. Crowley

ATTN J. Smith

Martin Marietta Corporation

Denver Division

P.O. Box 179

Denver, CO 80201

ATTN E. Carter

Martin Marietta Corporation

MP 148 Orlando Division

P.O. Box 5837

Orlando, FL 32805

ATTN W. Brockett

ATTN H. Cates

ATTN R. Gaynor

ATTN W. Janocko
McDonnell Douglas Corporation

5301 Bolsa Avenue

Huntington Beach, CA 92647

ATTN D. Fitzgerald

ATTN J. Holmgrem

McDonnell Douglas Corporation

Standards Engineering

P.O. Box 516

St. Louis, MO 63166

ATTN M. Stitch

ATTN D. Dohm

ATTN Library

McDonnell Douglas Corp. 3855 Lakewood Boulevard Long Beach, CA 90846 ATTN Tech. Lib.

Messenger, George C.

Consulting Engineer

3111 Bel Air Drive, 7-F

Las Vegas, Nevada 89109

Mission Research Corporation

1150 Silverado Street

P.O. Box 1209

La Jolla, CA 92038

ATTN J. Azarewicz

ATTN R. Berger

ATTN J. Raymond

ATTN V. Van Lint

Mission Research Corp.

735 State Street

Santa Barbara, CA 93202

ATTN C. Longmire

Massachusetts Institute of Technology

Lincoln Laboratory

P.O. Box 73

Lexington, MA 02173

ATTN P. McKenzie

ATTN Library A-082

Mitre Corporation

P.O. Box 208

Bedford, MA 01730

ATTN M. Fitzgerald

Motorola Government Electronics Division 8201 E. McDowell Road

Scottsdale, AZ 85252

ATTN A. Christensen 
Motorola Semiconductor Products, Inc.

P.O. Box 20912

Phoenix, AZ 85036

ATTN L. Clark

National Semiconductor Corp.

2900 Semiconductor Drive

Santa Clara, CA 95051

ATTN R. Wang

ATTN A. London

New Mexico University

Elec. Eng. \& Computer Science Dept

Albuquerque, NM 87131

ATTN H. Southward

Northrop Corporation

Northrop Research \& Technology Center

1 Research Park

Palos Verdes Peninsula, CA 90274

ATTN J. Srour

Northrop Corporation

Electronic Division Headquarters

1 Research Park

Palos Verdes Peninsula, CA 90274

ATTN T. Jackson

ATTN P. Eisenberg

Northrop Corporation

Electronic Division

2301 West 120th Street

Hawthorne, CA 90250
ATTN L. Apodaca
ATTN P. Gardner
ATTN D. Strobel

Physics International Company

2700 Merced Street

San Leandro, CA 94577

ATTN Div 6000

ATTN J. Huntington

ATTN J. Shea

R\&D Associates

P.O. Box 9695

4640 Admiralty Way

Marina del Rey, CA 90291

ATTN C. Rogers

ATTN R. Poll

Rand Corporation

1700 Main Street

Santa Monica, CA 90406

ATTN C. Crain
Raytheon Company

Advanced Design Dept.

Hartwell Road

Bedford, MA 01730

ATTN J. Ciccio

Raytheon Company

528 Boston Post Road

Sudbury, MA 01776

ATTN H. Flescher

ATTN A. Van Doren

RCA Corporation

Camden Complex

Front \& Cooper Streets

Camden, NJ 08012

ATTN E. Van Keuren

RCA Corporation

David Sarnoff Research Center

P.O. Box 432

Princeton, NJ 08540

ATTN D. OConnor

ATTN Office NI03

RCA Corporation

Missile \& Surface Radar

Bldg. 108-239, Marne Highway

Moorestown, NJ 08057

ATTN R. Killion

RCA Corporation

Government Systems Division

ASTRO Electronics Division

P.O. Box 800, Locust Corner

Princeton, NJ 08540

ATTN G. Bruckar

ATTN V. Mancino

RCA Corporation

Solid State Division

Box 3200

Somerville, NJ 08876

ATTN W. Allen

Rensselaer Polytechnic Institute P.O. Box 965

Troy, NY 12181

ATTN R. Gutmann

Research Triangle Institute

P.O. Box 23194

Research Triangle Park, NC 27709

ATTN Eng Div M. Simons Jr.

Rockwell International Corp.

5701 West Imperial Highway

Los Angeles, CA 90009

ATTN TIC BA08

ATTN T. Yates 
Rockwell International Corp.

Autonetics Group

3370 Miraloma Avenue

P.O. Box 3105

Anaheim, CA 92803
ATTN J. Bell
ATTN V. DeMartino
ATTN T. Oki
ATTN V. Strahan

Rockwell International Corp.

Space Division

12214 South Lakewood Boulevard

Downey, CA 90241

ATTN D. Stevens

Sanders Associates, Inc.

95 Canal Street

Nashua, NH 03060

ATTN M. Aitel

ATTN L. Brodeur

Science Applications, Inc.

2860 S. Circle Drive

Suite 2224

Colorado Springs, CO 80906

ATTN D. Stribling

Science Applications, Inc.

1200 Prospect Street

P.O. Box 2351

La Jolla, CA 92038

ATTN J. Naber

ATTN V. Orphan

ATTN V. Verbinski

Science Applications, Inc.

8400 Westpark Drive

McLean, VA 22101

ATTN W. Chadsey

Singer Company-Kear fott Div.

Dept. 5830

150 Totowa Road

Wayne, NJ 07470

ATTN R. Spiegel

Singer Company

Kearfott Division

$1150 \mathrm{McBride}$ Avenue

Little Falls, NJ 07424

ATTN J. Brinkman

Sperry Rand Corporation

Sperry Microwave Electronics

P.O. Box 4648

Clearwater, FL 33518

ATTN Engineering Laboratory
Sperry Rand Corporation

Sperry Division

Marcus Avenue

Great Neck, NY 11020

ATTN C. Craig

ATTN P. Maraffino

ATTN F. Scaravaglione

ATTN R. Viola

Sperry Rand Corporation

Sperry Flight Systems

P.O. Box 21111

Phoenix, AZ 85036

ATTN D. Schow

Sperry Univac

Univac Park

P.O. Box 3525

St. Paul, MN 55165

ATTN J. Inda

Spire Corporation

P.O. Box D

Bedford, MA 01730

ATTN R. Little

SRI International

333 Ravenswood Avenue

Menlo Park, CA 94025

ATTN A. Whitson

ATTN P. Dolan

Teledyne Ryan Aeronautical

Box 311

San Diego, CA 92112

ATTN J. Rawlings

Texas Instruments, Inc.

13500 N. Central Expressway

P.O. Box 5474, M.S. 262

Dallas, TX 75222

ATTN A. Peletier

ATTN R. Stehlin

TRW Incorporated

Defense and Space Systems Group One Space Park

Redondo Beach, CA 90278

ATTN O. Adams

ATTN P. Guilfoyle

ATTN H. Haid

ATTN H. Holloway

ATTN R. Kingsland

ATTN A. Pavelko

ATTN R. Schnieder

ATTN A. Witteles 
TRW Defense \& Space Sys Group

San Bernardino Operations

P.O. Box 1310

San Bernardino, CA 92402

ATTN M. Gorman

ATTN R. Kitter

ATTN F. Fay

TRW Systems and Energy

P.O. Box 368

Clearfield, Utah 84015

ATTN J. Spehar

ATTN D. Millward

Vought Corporation

P.O. Box 5907

Dallas, TX 75222

ATTN Library

ATTN Tech Data Ctr

ATTN R. Tomme

Westinghouse Electric Corporation

Radiation Effects Technology

P.O. Box $1521 \mathrm{M} / \mathrm{S} 3330$

Baltimore, MD 21203

ATTN D. Crichi

ATTN H. Kalapaca

Westinghouse Electric Corporation

Aerospace Division

P.O. Box 746, M/S 292

Baltimore, MD 21203

ATTN L. McPherson

\section{Other Organizations}

Aerospace Industries Association of America Inc.

1725 E. Sales Street, N.W.

Washington, DC 20036

ATTN S. Siegel

Electronic Industries Association

2001 Eye Street, N.W.

Washington, DC 20006

ATTN J. Hessman 
NBS.114A (REV. 7.73)

\begin{tabular}{|c|c|c|c|}
\hline $\begin{array}{l}\text { U.S. DEPT. OF COMM. } \\
\text { SIBLIOGRAPHIC DATA } \\
\text { SHEET }\end{array}$ & $\begin{array}{l}\text { 1. PUBLICATION OR REPORT NO. } \\
\text { NBSIR } 79-1723\end{array}$ & $\begin{array}{l}\text { 2. Gov't Accession } \\
\text { No. }\end{array}$ & 3. Recipient's Accession No. \\
\hline \multirow{2}{*}{\multicolumn{3}{|c|}{$\begin{array}{l}\text { 4. TITLE AND SUBTITLE } \\
\text { STANDARD PROCEDURE FOR USE OF THERMOLUMINESCENCE DOSIMETRY } \\
\text { IN RADIATION-HARDNESS TESTING OF ELECTRONIC DEVICES }\end{array}$}} & $\begin{array}{l}\text { 5. Publication Date } \\
\text { May } 1979\end{array}$ \\
\hline & & & 6. Performing Organization Code \\
\hline \multirow{3}{*}{\multicolumn{3}{|c|}{$\begin{array}{l}\text { 7. AUTHOR(S) } \\
\text { J.C. Humphreys and S.E. Chappe 11 } \\
\text { 9. PERFORMING ORGANIZATION NAME AND ADDRESS } \\
\text { NATIONAL BUREAU OF STANDARDS } \\
\text { DEPARTMENT OF COMMERCE } \\
\text { WASHINGTON, D.C. } 20234\end{array}$}} & 8. Performing Organ. Report No. \\
\hline & & & 10. Project/Task/Work Unit No. \\
\hline & & & 11. Contract/Grant No. \\
\hline \multirow{2}{*}{\multicolumn{3}{|c|}{$\begin{array}{l}\text { 12. Sponsoring Organization Name and Complete Address } \\
\text { Defense Nuclear Agency } \\
\text { W'ashington, D.C. } 20305\end{array}$}} & $\begin{array}{l}\text { 13. Type of Report \& Period } \\
\text { Covered }\end{array}$ \\
\hline & & & 14. Sponsoring Agency Code \\
\hline
\end{tabular}

15. SUPPLEMENTARY NOTES

16. ABSTRACT (A 200-word or less factual summary of most significant information. If document includes a significant bibliography or literature survey, mention it here.)

A standard recommended practice for the use of thermoluminescence dosimetry (TLD) systems has been developed. It is intended for the use of facilities that are engaged in the radiation-hardness testing of electronic components and systems. The practice has been written in the form of an ASTM standard for determination of absorbed dose in a medium as a result of photon or electron irradiation. It covers various aspects of TLD systems such as performance testing, dose calibration, and use procedures and precautions. A selected bibliography of TLD characteristics is included.

17. KEY WORDS (six to twelve entries; alphabetical order; capitalize only the first letter of the first key word unless a proper name; separated by semicolons)

Electronic devices; electrons, photons, radiation hardness; standard practice; thermoluminescence dosimeters
18. AVAILABILITY
Unlimited

For Official Distribution. Do Not Release to NTIS

[_. Order From Sup. of Doc., U.S. Government Printing Office Wa shington, D.C. 20402 , SD Cat. No. C13

Order From National Technical Information Service (NTIS) Springfield, Virginia 22151

\begin{tabular}{|l|c|}
\hline $\begin{array}{c}\text { 19. SECURITY CLASS } \\
\text { (THIS REPURT) } \\
\text { UNCL ASSIFIED }\end{array}$ & 21. NO. OF PAGES \\
\hline $\begin{array}{l}\text { 20. SECURITY CLASS } \\
\text { (THIS PAGE) } \\
\text { UNCLASSIFIED }\end{array}$ & $\begin{array}{l}\text { 22. Price } \\
\$ 5.25\end{array}$ \\
\hline
\end{tabular}




